\title{
LA NATURALEZA MODULAR DEL LENGUAJE: ¿UNA HIPÓTESIS QUE VINDICAR, QUE DESCARTAR O QUE REFORMULAR? ALGUNAS CONSIDERACIONES A PROPÓSITO DE LOS TRASTORNOS DEL LENGUAJE LIGADOS AL DESARROLLO
}

\author{
Antonio Benítez Burraco \\ Universidad de Huelva
}

\begin{abstract}
RESUMEN
Los modelos modulares ocupan un lugar preferente en la caracterización (biológica) de la Facultad del Lenguaje. Sin embargo, distintas evidencias, de muy diversa naturaleza, parecen cuestionar su idoneidad a la hora de describir por completo (y explicar satisfactoriamente) la manera en que se adquiere el lenguaje y especialmente, el modo en que se desarrollan y se organizan durante la ontogenia los centros neuronales implicados en el procesamiento lingüístico. Entre dichas evidencias, las relacionadas con el análisis fenotípico, cognitivo, neurobiológico y genético de los trastornos del lenguaje ligados al desarrollo ocupan un lugar destacado. Simultáneamente, cuando se examina con suficiente detalle cómo se regulan y tienen lugar los procesos de desarrollo en los organismos vivos, la modularidad emerge como una propiedad básica a todos los niveles de complejidad biológica. Algunos modelos recientes de la Facultad del Lenguaje (en especial, los derivados del Programa Minimalista chomskyano) parecen compatibles con el relevante papel que otorga la moderna biología del desarrollo a la modularidad en lo concerniente a la organización, el desarrollo y la evolución de los seres vivos. De hecho, convenientemente reexaminados a la luz de dicho papel, se muestran capaces de caracterizar satisfactoriamente la ontogenia lingüística, explicando, asimismo, el complejo escenario resultante del análisis de los trastornos lingüísticos ligados al desarrollo, y poniendo de manifiesto, en definitiva, que la hipótesis modular del lenguaje, en lugar de descartarse, debe seguir vindicándose, si bien dicha vindicación debe ir acompañada de una imprescindible reformulación que tenga en cuenta los avances acaecidos en el campo de la (Neuro)Biología.
\end{abstract}

Palabras clave: Facultad del Lenguaje, innatismo, modularidad, ontogenia, sistemas de desarrollo, trastornos del lenguaje.

\section{AbSTRACT}

Modular models of the mind/brain probably represent the commonest (and most appealing) way of depicting the (biological) nature of the Faculty of Language. Nevertheless, there exist diverse evidences which seem to put into question the appropriateness of such models for comprehensively describing and satisfactorily 
explaining how language is acquired, but particularly how neuronal devices involved in language processing grow and become arranged at the term of development. Among several others, those resulting from the phenotypic, cognitive, neurobiological, and genetic analyses of developmental language disorders should be highlighted. At the same time, when we seriously examine the real way in which developmental processes take place in all organisms, modularity emerges as a pervasive property of biological systems at all levels of complexity. Some fresh models of the Faculty of Language (particularly, those rooted in the chomskyan Minimalist Program) seem to be pretty compatible with the relevant role dispensed by modern evolutionary developmental biology (evo-devo) to modularity pertaining to the structure, development, and evolution of living beings. In fact, when properly revised in the light of such a key role, these new models not only accurately depict the ontogeny of language, but also adequately explain the intricate scenario emerging from the analysis of that kind of disorders. Ultimately, they suggest that the very modular hypothesis should not be discarded, but vindicated, though such a vindication clearly demands a previous reformulation of the original model according to current (neuro) biological data.

Key Words: developmental systems, Faculty of Language, language disorders, modularity, nativism, ontogeny.

RECIBIDO: 23/12/2010

APROBADO: 28/11/2011

\section{INTRODUCCIÓN}

Probablemente no resultaría exagerado afirmar que los últimos cincuenta años de análisis del lenguaje han conducido a una notable biologización de la Lingüística, hasta el punto de llegar a sugerirse que esta disciplina debería considerarse como una rama de la Biología (Chomsky 1986, p. 27; 2000a, p. 90). Sea como fuere, y en relación con dicho análisis, estos años han sido indudablemente testigos de un progresivo «shift of focus [...] from the study of behavior and its products to the study of systems of mental representation and computation» (Chomsky 1986, p. 51). Durante este tiempo se ha ido acumulando un importante corpus de evidencias que parece legitimar la pertinencia (y la necesidad) de ese análisis biológico del lenguaje, entre las cuales cabe destacar:

(i) la presencia en otras especies de capacidades homólogas a las implicadas en el procesamiento lingüístico,

(ii) la existencia de restos fósiles de especies extintas que cabe relacionar con estructuras biológicas (y sus actividades) vinculadas al lenguaje en la nuestra,

(iii) diferentes aspectos del proceso de adquisición del lenguaje (e implícitamente del conocimiento gramatical finalmente adquirido y de la propia estructura de las lenguas) que sugie- 
ren que el desarrollo lingüístico precisa de (y se explica mejor remitiendo a) algún tipo de información no derivable de la experiencia (en esencia, innata),

(iv) la constatación de que la ocurrencia de alteraciones estructurales y/o funcionales en determinadas regiones cerebrales compromete determinados aspectos del procesamiento del lenguaje (una línea de investigación que arranca con los trabajos seminales de Broca, Wernicke y Lichteim en el siglo XIX, y que se prolonga en nuestros días en los modernos estudios de afasiología), y

(v) la existencia de trastornos del lenguaje de carácter hereditario, los cuales entrañan, asimismo, la aparición de diversas alteraciones estructurales y/o funcionales de determinadas áreas cerebrales durante y al término de la ontogenia.

Diversos modelos neurolingüísticos y psicolingüísticos tratan de describir y explicar el modo en que se desarrolla y se organiza el sustrato neuronal del lenguaje, y en que tiene lugar el procesamiento lingüístico en el cerebro de los hablantes. En lo fundamental, la similitud o la disimilitud entre los diversos modelos responde a si conciben los mecanismos y dispositivos mentales/cerebrales inherentes a la Facultad del Lenguaje (esto es, la capacidad que posee la mente/cerebro de adquirir una lengua y hacer uso de ella; en adelante, FL) como idiosincrásicos o como compartidos (en mayor o menor medida) con otras capacidades cognitivas, aunque también, a si los estímulos recibidos por el individuo durante el desarrollo son suficientes para garantizar al final del mismo la aparición de una arquitectura neuronal con tales características.

Uno los modelos más conocidos a este respecto es el chomskyano. Hasta la década de los años noventa del pasado siglo Chomsky venía concibiendo el lenguaje como una facultad cognitiva sustancialmente independiente, que sería en gran medida el resultado de un dispositivo gramatical autónomo que impondría una forma (gramatical) al pensamiento con objeto de poder transmitirlo. Adicionalmente, el conocimiento gramatical alcanzado por el individuo adulto (tradicionalmente denominado «competencia») solo podría adquirirse merced al acceso durante el desarrollo a información gramatical relevante no derivable de los datos lingüísticos primarios (esto es, la combinación de sonidos y experiencias extralingüísticas a la que se ve expuesto el niño; en adelante, DLP), la cual sería, en consecuencia, innata. Históricamente, dicha información se denominó Gramática Universal (en adelante, GU). Esta GU constituiría, por consiguiente, un estado inicial altamente articulado, entendido como un sistema de conocimiento autónomo basado en categorías y principios irreducibles a los de otros sistemas cognitivos, 
esto es, específicos de dominio. Por expresarlo en los términos usados por el propio Chomsky, la GU sería «a system of conditions deriving from the human biological endowment that identifies the I-languages that are humanly accessible under normal conditions» (Chomsky 1986, p. 23). El papel de la GU durante la adquisición consistiría en restringir el número de gramáticas que pueden construirse potencialmente a partir de los DLP (o acaso, en priorizar alguna[s] de ellas sobre las restantes) y en aportar aquellas restricciones que resultan imposibles de deducir de un input que carece de evidencias negativas. Ahora bien, lo verdaderamente relevante para la cuestión que nos ocupa es que el lenguaje tendría, en atención a todo lo discutido, un carácter doblemente modular, desde el momento en que lo sería la propia FL en relación con la cognición y, a su vez, los distintos subsistemas que componen la primera. Precisemos que se trataría, en lo sustancial, de una concepción de la modularidad que remitiría a la de Fodor 1983, para quien «módulo» venía a ser todo dispositivo computacional autónomo de carácter innato, informativamente encapsulado, que presenta una especificidad de dominio y que habría evolucionado de forma independiente para desempeñar una determinada función. Ciertamente, Fodor restringía este carácter modular a los dispositivos de procesamiento periféricos (y, en particular, a los sistemas sensoriales). Sin embargo, no es menos cierto que, en la línea de la FL chomskyana, el concepto «modular»se amplió muy pronto para dar cabida a todo tipo de capacidades cognitivas de nivel superior (Pinker, 1994; Spelke 1998; Sperber 2001; v. infra), y también para describir y explicar los déficits asociados a su disfunción, incluyendo todo tipo de trastornos de la cognición adquiridos y ligados al desarrollo, y por consiguiente, también los de carácter lingüístico, como la dislexia (Frith 1986) o el trastorno específico del lenguaje (Gopnik 1997) (el caso del síndrome de Williams-Beuren, muy ilustrativo a este respecto, se discute en detalle en $\$ 4$ ). En todo caso, aquel concepto de módulo remitía, asimismo, a una segunda asunción fundamental del modelo chomskyano, a saber, que la naturaleza y la fuente en términos ontogenéticos del conocimiento apriorístico que representa la GU no solo es de naturaleza innata, sino específicamente de carácter genético. Como afirma Chomsky, la GU sería «a common human attribute, genetically determined, one component of the human mind» (Chomsky 1977, p. 164), de tal modo que «through interaction with the environment $[. .$.$] this faculty of mind becomes articulated and refined,$ emerging in the mature person as a system of knowledge of language [i.e. a grammar of his native language]» (ibid.). El resultado de lo que el propio Chomsky 1986, p. 6, llegaría a denominar el segundo giro conceptual de su teoría acerca de la naturaleza del lenguaje fue que dicha teoría terminó equivaliendo a «a specific theory of genetic factors in the acquisition of this knowledge [of one's own language] or the develop- 
ment of these systems of mental representation [which ultimately constitute such a knowledge]» (Matthews 2001, p. 97).

A pesar del reconocimiento alcanzado, esta caracterización del lenguaje y de la ontogenia lingüística dista de ser universalmente aceptada. De hecho, diversas evidencias de carácter psicolingüístico, neurolingüístico y neurobiológico, concernientes al proceso de adquisición del lenguaje a lo largo del desarrollo, pero también al modo en que tiene lugar el procesamiento lingüístico en el individuo adulto, parecen cuestionarla (v. \$2). Del mismo modo, la hipótesis de un lenguaje innato (o cuando menos, de la existencia de información gramatical codificada en los genes) es rechazada por quienes aducen que, en todo caso, sería preferible hablar de una habilidad genéticamente codificada para aprenderlo, sugiriendo que los procesos que intervendrían en la adquisición del lenguaje serían los mismos que estarían implicados en la adquisición de otras capacidades cognitivas (Greenfield 1991; Bates et al. 1992; Elman et al. 1996; v. también \$2). Finalmente, el posible itinerario evolutivo del lenguaje -que no solo constituye otro campo de especial interés en la actualidad, sino un aspecto de consideración obligada en cualquier discusión acerca del carácter modular e innato del lenguaje, toda vez que, en atención a la anterior caracterización (ampliada) de módulo, este debería constituir una respuesta evolutiva a un problema adaptativo concreto- es también objeto de importantes controversias, que se centran fundamentalmente en si la aparición del lenguaje puede explicarse mediante el mecanismo de «descenso con modificación» vindicado por el darwinismo ortodoxo (para una revisión, v. Benítez Burraco 2009a y las citas contenidas allí). En realidad, el modelo anterior ni siquiera representa el punto final del pensamiento chomskyano, puesto que tras el desarrollo del denominado Programa Minimalista (Chomsky 1995; 2000a) dicho pensamiento ha evolucionado hacia lo que podría denominarse un innatismo sin GU o un innatismo general (cf. O'Grady 2003), aunque sin renunciar por completo a que determinados aspectos de la FL deriven de principios específicos de dominio (v. $\$ 5$ y especialmente $§ 6$ ). En esencia, dicha evolución ha supuesto, paradójicamente, un distanciamiento de la conceptualización del lenguaje como un sistema de conocimiento basado en principios composicionales altamente específicos y faltos de correspondencia con los que rigen otros dominios cognitivos (Lorenzo 2006, pp. 96-98).

Simultáneamente, la vigencia de facto de este modelo se antoja difícilmente cuestionable en buena parte de las áreas de investigación de mayor relevancia y pujanza en el ámbito de los estudios del lenguaje. Por un lado, y como acertadamente discuten Longa y Lorenzo 2008, a dicho modelo sigue anclada la teoría actual de la adquisición, al menos la que se adhiere a las premisas formalistas (esto es, la que defiende, en lo fundamental, que la adquisición del lenguaje viene determinada 
por la estructura de la mente, que el mecanismo de adquisición es deductivo, que el estado inicial contempla determinados conocimientos innatos, que conocer implica imponer una estructura a la experiencia, que el papel de la experiencia consiste en refutar o validar los modelos gramaticales, y que el proceso tiene un carácter intensional). Para esta teoría de la adquisición la clave para la resolución del Problema de la Proyección -esto es, el reto al que se enfrenta el niño de alcanzar el conocimiento gramatical adulto a partir de los DLP (Baker 1979) - radica en la imposición a dichos datos de la naturaleza y la estructura de las unidades sintácticas (en esencia, una teoría de la gramática), las cuales resultarían conocidas a priori (Gleitman 1990, entre otros muchos). Por otro lado, la mayoría de los análisis neurolingüísticos encaminados a esclarecer la organización del sustrato neuronal del lenguaje en el individuo adulto parte de la premisa de la necesidad (y la posibilidad) de establecer correlaciones (idealmente unívocas) entre, por un lado, los diferentes niveles, computaciones y categorías lingüísticos, tal como son definidos y caracterizados por la Lingüística, y, por otro, porciones específicas del tejido neuronal, dedicadas de forma exclusiva (en principio) al procesamiento del lenguaje (en esencia, «áreas del lenguaje» o «centros del lenguaje») (v. §2). Esto se realizaría a través la búsqueda y la caracterización de dobles disociaciones (entre el lenguaje y la cognición, y entre los diversos subcomponentes del primero), pero, merced también al análisis de la actividad cerebral durante el procesamiento de tareas específicas de índole lingüística. Finalmente, las evidencias que parecen corroborar el carácter innato del lenguaje (cf. Benítez Burraco 2008 para una revisión), y por consiguiente, la hipótesis de que el desarrollo de la FL no responde únicamente a estímulos ambientales, sino que demanda del concurso de información «interna», se ha reducido habitualmente, y en la línea de lo sugerido por el propio Chomsky (v. supra), a la existencia de un genotipo lingüístico, entendido como «that part of our genetic endowment that is relevant for our linguistic development» (Anderson y Lightfoot 1999, p. 702), el cual, en presencia de los DLP, daría lugar al conocimiento lingüístico que posee el individuo adulto, esto es, al fenotipo lingüístico (ibid., pp. 711, 712). Nos encontraríamos, por consiguiente, ante una concepción biológica del lenguaje que respondería satisfactoriamente a la mayor parte de los ítems definitorios del módulo fodoriano: encapsulamiento informativo, especificidad de dominio, carácter innato, etc. (y una vez más, con independencia de que, en origen, dicha caracterización estuviese restringida a los dispositivos periféricos de entrada).

No cabe duda de que el término «modular» adolece en las ciencias cognitivas de un carácter excesivamente impreciso (v. Barrett y Kurzban 2006 para una discusión detallada, pero también §5). Simultáneamente, la naturaleza modular exacta de la cognición (y por inclusión, del 
lenguaje) ha sido objeto de una importante controversia en las últimas décadas (Fodor 1983; Chomsky 1986; Karmiloff-Smith 1992; Smith y Tsimpli 1995; Anderson y Lightfoot 1999; Coltheart 1999; entre otros muchos; v. Barrett y Kurzban 2006 para una revisión). No es la intención principal de este trabajo realizar una revisión crítica del concepto de modularidad aplicado al análisis de la cognición en general y del lenguaje en particular (aunque v. supra y \$ 5), como tampoco lo es discutir las diversas versiones que existen de la hipótesis modular (v. Barrett y Kurzban 2006 en este sentido, aunque también §5). Por el contrario, su objetivo fundamental es revisar específicamente las evidencias relacionadas con los trastornos del lenguaje (en especial, los ligados al desarrollo) que parecen cuestionar el modelo modular de lenguaje descrito anteriormente, una vez más, por ser el de más éxito y por constituir el fundamento de buena parte de las teorías de adquisición del lenguaje y de los modelos neurolingüísticos y psicolingüísticos en uso actualmente. Un objetivo adicional será discutir si la entidad de tales evidencias exige el abandono de dicho modelo en particular (justificando, si se quiere, lo acertado de la evolución del pensamiento chomskyano), o incluso, de los modelos modulares del lenguaje en general, en favor de hipótesis alternativas, o si por el contrario, el concepto de «modularidad» resulta imprescindible para entender la genuina naturaleza (biológica) del lenguaje y describir la FL a todos los niveles de complejidad, de modo que lo que realmente se precisaría, a la luz de tales evidencias, sería una reformulación del modelo original. Esta será, de hecho, la tesis fundamental que se defenderá en este trabajo, apoyándose para ello, además de en las evidencias a las que se hizo referencia anteriormente, en los recientes avances producidos en el campo de la biología del desarrollo de carácter evolutivo (en adelante, evo-devo).

\section{EVIDENCIAS QUE PARECEN CUESTIONAR EL CARÁCTER MODULAR DEL LENGUAJE}

Como se apuntaba en el apartado anterior, diversas evidencias, de distinta naturaleza, parecen cuestionar la naturaleza modular del lenguaje y en particular, el modelo modular concreto que parece haber tenido mayor aceptación entre los estudiosos del lenguaje y cuyas características se describieron en $\S 1$. Dichas evidencias podrían agruparse en cuatro categorías fundamentales, diferentes aunque necesariamente interrelacionadas:

a) Evidencias (psico)lingüísticas concernientes al proceso de adquisición del lenguaje, y en particular, a la naturaleza de los DLP y a su capacidad para permitir per se la consecución del cono- 
cimiento gramatical finalmente alcanzado por el individuo al término del desarrollo. Se trataría, en otras palabras, de evidencias que cuestionarían la hipótesis de que la adquisición solo es posible en presencia de un conocimiento gramatical apriorístico o, cuando menos, de sistemas de aprendizaje sometidos a determinadas restricciones (cf. Hauser et al. 2002).

b) Evidencias neurolingüísticas y neurobiológicas concernientes a la organización estructural y funcional del supuesto módulo lingüístico a nivel cerebral, y por consiguiente, al tipo de mecanismos computacionales implicados en el procesamiento del lenguaje. Se trataría de evidencias que cuestionarían, en lo fundamental, la existencia de regiones cerebrales dedicadas de forma exclusiva al procesamiento de estímulos lingüísticos («áreas del lenguaje») y cuya disfunción daría lugar a déficits (y trastornos) exclusivamente lingüísticos.

c) Evidencias genéticas (aunque no solo) concernientes a los mecanismos implicados en la regulación del desarrollo (del sustrato neuronal) del hipotético módulo lingüístico. Se trataría de evidencias que descartarían la existencia de información genética específicamente lingüística (entiéndase por ello no ya información gramatical codificada en los genes, sino, cuando menos, genes concretos implicados de forma exclusiva en el desarrollo y el funcionamiento de las «áreas del lenguaje»).

d) Evidencias de carácter filogenético concernientes al origen evolutivo del hipotético módulo lingüístico. Se trataría de evidencias que cuestionarían que dicho módulo hubiese aparecido de forma independiente en respuesta a presiones selectivas específicas.

Con respecto a las evidencias de tipo (a), que se han revisado con detalle en otro lugar (Benítez Burraco 2008), da la impresión de que, a pesar de haber sido objeto de un exhaustivo análisis y de un prolongado debate, han permitido llegar únicamente a una suerte de tablas o de equilibrio (inestable) entre las hipótesis innatistas/formalistas y las funcionalistas/empiristas. Las primeras se apoyan fundamentalmente en la conocida paradoja de la "pobreza del estímulo» (Chomsky 1980, p. 34; Pullum y Scholtz 2002) para defender que en lo que atañe a la adquisición del lenguaje «whatever system is responsible must be biased or constrained in certain ways» (Hauser et al. 2002, p. 1577). La nómina de evidencias adicionales es considerablemente más extensa, desde luego, puesto que también incluye la existencia de casos en los que la adquisición se produce en ausencia de un input perceptivo directo, la similar periodización de la ontogenia lingüística en todos los individuos (en ocasiones, en ausencia de dichos estímulos), la presencia y la funcionalidad desde el momento del nacimiento (e incluso antes) de meca- 
nismos capaces de discriminar y clasificar propiedades relevantes del input lingüístico, la universalidad de los procesos de criollización de los sabires empleados como input lingüístico para una nueva generación de hablantes, las semejanzas que existen (a todos los niveles) entre la lenguas habladas y las de signos, o la existencia de rasgos estructurales comunes a todas las lenguas humanas (universales lingüísticos que se han venido interpretando como restricciones abstractas que afectan a la forma de la gramática de cualquier lengua humana y a la naturaleza de las categorías con las que opera dicha gramática, erigiéndose de este modo en propiedades biológicamente necesarias de la FL).

Por el contrario, los modelos empiristas/funcionalistas defienden que los procesos que intervendrían en la adquisición del lenguaje serían los mismos que permiten la adquisición de otras habilidades cognitivas y que el lenguaje podría adquirirse en ausencia de un conocimiento gramatical preexistente. En último término se llega a sostener que el objetivo de la adquisición no sería la interiorización de una competencia gramatical en los términos formulados por la teoría chomskyana, sino la consecución de un sistema de actuación de carácter más pragmático (cf. Newmeyer 1997; Seidenberg y MacDonald 1999, p. 574). Para ello, y frente a las anteriores evidencias, dichos modelos aducen, por ejemplo, que la supuesta «pobreza del estímulo» no sería tal, o que la adquisición es posible merced al aprendizaje estadístico (o aprendizaje dependiente de los datos), la imitación y/o la enseñanza (para una revisión de tales evidencias, así como de las objeciones planteadas a ellas por los modelos innatistas/formalistas, v. Benítez Burraco 2008).

Seguramente como reflejo de la situación de equilibrio a la que se aludía anteriormente, muchos trabajos recientes en el área (cf. Saxton 2010) se sitúan a medio camino entre la asunción tradicional de que los mecanismos de aprendizaje generales desempeñarían un papel complementario en la adquisición del lenguaje (reflejo de la primacía de los modelos formalistas) y la vindicación de la capacidad de estos mecanismos para alcanzar la totalidad del conocimiento gramatical (tal como defienden los modelos empiristas). Así, se sostiene que la separación entre lo innato y lo adquirido es en realidad artificial, puesto que ambos tipos de factores, los internos y los externos, se influyen mutuamente y son igualmente necesarios para que el proceso de adquisición llegue a término, incluso en lo concerniente a aspectos nucleares del lenguaje (paradigmáticamente, la capacidad de procesamiento sintáctico). En realidad, una de las hipótesis que defenderá este trabajo es que esta tradicional oposición entre nature y nurture se ve reconciliada (y es, por consiguiente, insostenible) a otros niveles de complejidad biológica de la FL (en particular, los que representan los dispositivos neuronales y los mecanismos reguladores del desarrollo). Consecuentemente, si no se atiende al modo en que se produce dicha reconciliación, no será 
posible entender la manera en que se desarrolla y se estructura la FL al término de la ontogenia. Por lo demás, lo anterior parece justificar (y demandar) el examen de evidencias neurolingüísticas y neurobiológicas, cada vez más numerosas, si lo que se pretende es dilucidar esta controvertida cuestión del carácter modular del lenguaje. Serán, por consiguiente, las evidencias de tipo (b) y (c) las de genuino interés para este trabajo, especialmente en relación con los trastornos del lenguaje ligados al desarrollo, en la línea de lo apuntado al final del apartado anterior. En lo concerniente a las evidencias de tipo (d), que se han examinado también en otro lugar (Benítez Burraco, 2009a), se dejarán, asimismo, a un lado, en buena medida porque los argumentos que resultarán válidos en términos ontogenéticos en relación con las evidencias de tipo (b) y (c) (v. §5), lo serán igualmente en términos filogenéticos.

\section{EVIDENCIAS NEUROLINGÜÍSTICAS Y NEUROBIOLÓGICAS QUE PARECEN CUESTIONAR EL CARÁCTER MODULAR DEL LENGUAJE}

Tal como se apuntó en $\S 1$, serían dos las implicaciones fundamentales del carácter modular del lenguaje (y en particular, del modelo concreto allí discutido). Por un lado, que deberían existir dobles disociaciones (a nivel psicolingüístico, y supuestamente también a nivel neurolingüístico y neurobiológico) entre el lenguaje y las restantes capacidades cognitivas, así como entre los diversos subcomponentes del primero. Por otro, que debería existir, asimismo, un genotipo lingüístico, el cual, integrado por genes encargados específicamente de la regulación del desarrollo (y el funcionamiento) de dicho módulo, sería responsable, en último extremo, de todas sus propiedades distintivas y, en particular, de su carácter innato.

Ahora bien, los estudios afasiológicos se enfrentan recurrentemente a un escenario que dificulta la delimitación precisa de los correlatos neuronales de los diversos niveles, computaciones, funciones y categorías lingüísticos. Así, sucede que:

(i) las lesiones susceptibles de ser analizadas cuentan generalmente con un tamaño y un alcance aleatorios, pudiendo afectar a áreas implicadas en diferentes procesos (lingüísticos o no), lo que puede dificultar la correcta interpretación de los síntomas observados y, en último término, el establecimiento de las diversas categorías clínicas;

(ii) consecuentemente, la clasificación clínica basada en la localización de lesiones no coincide necesariamente con la clasificación de carácter sintomático (v. infra); 
(iii) los síntomas (y déficits) advertidos en un mismo individuo pueden verse modificados con el tiempo;

(iv) los individuos que presentan un cuadro clínico mixto son mayoritarios;

(v) los factores emocionales y/o pragmáticos influyen habitualmente en la capacidad de producción/recepción del sujeto analizado; y

(vi) determinados déficits (primarios) pueden dar lugar a otros déficits (secundarios) diferentes, como sucede típicamente con el efecto que ejerce sobre las tareas de producción la existencia de algún déficit de comprensión.

A pesar de la ventaja que supone la aplicación de las técnicas de neuroimagen no invasivas al examen de los afectados por trastornos del lenguaje adquiridos, lo cierto es que en la inmensa mayoría de los casos clínicos documentados hasta la fecha no se ha podido determinar de forma concluyente la existencia de una disociación completa entre el lenguaje y otras capacidades cognitivas, ni, de forma más precisa, entre la competencia lingüística y otros sistemas cognitivos implicados en la actuación. Adicionalmente, la disfunción de la primera que se observa en la mayoría de los individuos afásicos afecta a aspectos generales del lenguaje y no de modo exclusivo a procesos, entidades o categorías gramaticales concretas tal como son definidas por la Lingüística (Newmeyer 1997). Un ejemplo paradigmático de las dificultades que entraña el establecimiento de disociaciones intralingüísticas a este nivel lo constituyen las afasias de Broca y Wernicke. Así, mientras que, por un lado, los síntomas asociados tradicionalmente a ambos tipos de afasias parecen deberse a la disfunción de áreas corticales más extensas (cf. Mohr et al. 1978 para el caso de la afasia de Broca, y Selnes et al. 1983 y Dronkers et al. 2000, para la de Wernicke), sucede, por otro, que la disfunción (traumática) de las regiones corticales de dicho nombre parece dar lugar a síntomas adicionales a los asociados tradicionalmente a tales afasias, como ocurre, por ejemplo, con los problemas de comprensión de índole sintáctica observados en pacientes en los que está dañada el área de Wernicke (Schwartz et al. 1987; Shapiro et al. 1993).

En realidad, tampoco la aplicación de las técnicas de neuroimagen no invasivas al análisis del procesamiento lingüístico en individuos sanos ha contribuido a esclarecer este confuso panorama, en el sentido de poder adscribir de manera unívoca regiones cerebrales concretas a funciones lingüísticas o componentes gramaticales específicos tal como son caracterizados por la Lingüística. Así, la naturaleza y la extensión de las supuestas «áreas del lenguaje» difieren (en cierta medida) según la naturaleza de las tareas de computación que es preciso realizar (como cabría seguramente esperar), pero también lo hacen de un individuo a 
otro durante la realización de una misma tarea. Asimismo, su localización precisa varía (en cierta medida) a lo largo de la ontogenia, con el aprendizaje de una segunda (o tercera) lengua y en función de la historia (clínica) del individuo y, en general, en virtud del ambiente lingüístico al que se ha visto expuesto durante su desarrollo (Bates $e t$ al. 1992; Dehaene et al. 1997; Thomas et al. 1997; Müller et al. 1999; Deacon 2000). Un segundo problema a este nivel estriba en que las áreas finalmente identificadas difícilmente pueden considerarse como dedicadas de manera exclusiva al procesamiento de estímulos de carácter lingüístico -es cierto, no obstante, que la capacidad resolutiva de este tipo de técnicas (Koizumi 2004) no permite rechazar por completo la posibilidad de que dentro de las áreas que parecen ser multifuncionales pueda existir alguna clase de disociación histológica entre diferentes tipos celulares y/o circuitos neuronales encargados de procesos lingüísticos específicos-. Así, por ejemplo, existen nutridas evidencias de que los ganglios basales desempeñan un papel muy significativo durante el procesamiento lingüístico, en particular, en tareas computacionales relacionadas con la fonación y la sintaxis (Ullman 2001; Lieberman 2000; 2002; 2006; v. también § 6). Sin embargo, dicha estructura subcortical se encarga, asimismo, del procesamiento de otros tipos de acciones secuenciales, tanto de índole motora como cognitiva, con objeto de permitir tareas rutinarias, y también para lograr su modificación en respuesta a cambios ambientales que demandan una alteración de dichas tareas (Marsden y Obeso 1994; Graybiel 1995; Monchi et al. 2001). En definitiva, si algo parece sugerir este tipo de estudios neuroanatómicos y neurofisiológicos sería la existencia de una interrelación entre el lenguaje y otras capacidades cognitivas en lo que atañe a la organización y el funcionamiento de los centros cerebrales responsables de su procesamiento a nivel neuronal, desde el momento en que los circuitos que los sustentan podrían ser muy parecidos o incluso parcialmente compartidos (cf. Nobre y Plunkett 1997).

Los trastornos del lenguaje adquiridos están causados por alteraciones estructurales y/o funcionales de los dispositivos neuronales implicados en el procesamiento lingüístico debidas a la ocurrencia de accidentes cardiovasculares, procesos tumorales, daños traumáticos, o procesos patológicos o neurodegenerativos. Por el contrario, el origen de los trastornos del lenguaje ligados al desarrollo se encuentra, en principio, en una mutación genética, aunque en rigor, en la alteración de cualquiera de los parámetros que, en términos de paridad, integran los sistemas de desarrollo $(\$ 5)$. Consecuentemente, su análisis no tiene como objeto fundamental determinar las consecuencias de la disfunción de un determinado componente del sistema adulto intacto, sino analizar itinerarios ontogenéticos alternativos de la FL. Necesariamente, la consideración de este tipo de afecciones posee un interés aún mayor 
que el de los trastornos adquiridos en lo concerniente a la hipotética naturaleza modular del lenguaje. En principio, se han descrito diferentes trastornos cognitivos de esta clase en los que solo el lenguaje parece estar afectado (y que poseen simultáneamente un carácter hereditario, lo que descartaría que pudieran deberse al efecto del ambiente en que se produce el desarrollo). Entre otros cabe mencionar la dislexia, el TEL (un acrónimo para «trastorno específico del lenguaje») o el SSD (un acrónimo para speech-sound disorder, esto es, trastorno de los sonidos del habla), así como algunas otras afecciones de prevalencia muy baja, como el síndrome de Landau-Kleffner, la epilepsia rolándica (o silviana) con dispraxia verbal, o el síndrome de la deleción del cromosoma 22q13 (para una revisión, v. Benítez Burraco 2009b, pp. 83-227). En general, la hipótesis de trabajo más común en relación con tales trastornos es que se caracterizan, efectivamente, por la presencia de síntomas exclusivamente lingüísticos, que serían el resultado de uno o más déficits cognitivos subyacentes de naturaleza también exclusivamente lingüística, los cuales serían a su vez consecuencia de la disfunción de una (o de varias) áreas cerebrales dedicadas al procesamiento del lenguaje (en principio, de forma exclusiva); en último término, dicha disfunción sería el resultado de la mutación de genes implicados (en principio, también de forma exclusiva) en la regulación del desarrollo y el funcionamiento de dichas áreas.

No obstante, el análisis exhaustivo a diversos niveles de complejidad biológica (fenotípico/clínico, cognitivo, neuroanatómico, neurofisiológico y genético) de este tipo de trastornos ha dado lugar a un significativo cúmulo de evidencias que parecen cuestionar a todos esos niveles su supuesto carácter específicamente lingüístico:

a) desde el punto de vista clínico, los trastornos específicos del lenguaje se caracterizan por su naturaleza heterogénea, de modo que las distintas categorías que representan no parecen aprehender de forma adecuada la variabilidad sintomática que manifiestan los individuos afectados. Esta circunstancia ha llevado a postular la existencia de diferentes subtipos, cuya característica distintiva suele ser la disfunción más acusada de alguna de las capacidades implicadas en el procesamiento del lenguaje, si bien resulta cuestionable hasta qué punto reflejan entidades o procesos de interés desde el punto de vista lingüístico. Así, por ejemplo, en el caso del TEL, los distintos subtipos se han agrupado en tres categorías fundamentales: fonológica, expresiva y expresivo-receptiva (sic) (cf. Rapin y Allen 1993; American Psychiatric Association 1994). Al mismo tiempo, los resultados obtenidos por los individuos afectados en las pruebas psicolingüísticas empleadas para el diagnóstico son compatibles con la presencia simul- 
tánea (comorbilidad) de diferentes trastornos específicos del lenguaje, aunque también de trastornos en los que tanto el lenguaje como otras capacidades cognitivas se hallan afectados. Así, y por seguir centrados en el mismo trastorno, el TEL es frecuentemente comórbido con la dislexia (Smith et al. 1996; Catts et al. 2005), pero también con el SSD (Shriberg et al. 1999) y con el autismo (Norbury 1995; Tager-Flusberg 2006). Por lo demás, y al igual que sucedía en el caso de los trastornos del lenguaje adquiridos, en la mayoría de los casos clínicos documentados hasta la fecha en los que se observa una disfunción del lenguaje, dicha disfunción no parece afectar necesariamente de forma exclusiva a ninguna de las entidades, funciones o fenómenos lingüísticos que contemplan los diferentes modelos teóricos desarrollados desde el campo de la Lingüística (cf. Newmeyer 1997).

b) A nivel cognitivo, y tratando de reconciliar (y explicar) la variabilidad observada desde el punto de vista sintomático con la comorbilidad que también suele advertirse a dicho nivel, se ha sugerido indistintamente:

(i) que este tipo de trastornos estaría causado por un déficit subyacente más general (esto es, no específicamente lingüístico) (cf. Nobre y Plunkett 1997), el cual podría manifestarse en ciertas poblaciones y/o circunstancias como un trastorno (específicamente) lingüístico (de ahí la heterogeneidad y/o la comorbilidad observadas);

(ii) que la aparición de un determinado trastorno respondería a la presencia simultánea de dos o más déficits subyacentes (en algunos casos no específicamente lingüísticos), cada uno de los cuales contribuiría en cierta medida al fenotipo observado (en otras palabras, que las entidades clínicas que representan estos trastornos consistirían realmente en conglomerados de diferentes disfunciones caracterizadas por una sintomatología parecida), teniendo presente, una vez más, que tales déficits pueden manifestarse en determinadas poblaciones y/o circunstancias como otros trastornos diferentes, específicamente lingüísticos o no (y de ahí, en conjunto, la heterogeneidad y/o la comorbilidad observadas).

Así, por ejemplo, la disfunción de la memoria fonológica parece constituir el déficit nuclear del TEL (Bishop 2002), la dislexia (Shaywitz et al. 1998) y el SSD (Shriberg et al. 1999); al mismo tiempo, un déficit en la capacidad de procesamiento (y discriminación) de impulsos sensoriales de tipo acústico (lingüísticos o no lingüísticos) que se suceden a gran velocidad parece contribuir tanto a la aparición de la dislexia (Temple et al. 2000), 
como del TEL (Tallal y Pierce 1973; Tallal et al. 1991), si bien es plausible que origine también trastornos auditivos de carácter no lingüístico, toda vez que dicho déficit afecta a todas las modalidades acústicas. En el caso concreto de la dislexia, otros déficits adicionales, igualmente de carácter no específicamente lingüístico, podrían contribuir a la aparición del trastorno, como sería el caso de una disfunción cerebelar (Nicolson y Fawcett 2006), un déficit en la capacidad de procesamiento de estímulos de índole visual (Lovegrove et al. 1980) o una disfunción de la vía magnocelular (Livingstone et al. 1991; Stein y Walsh 1997).

c) A nivel neuroanatómico y neurofisiológico, este tipo de trastornos suele conllevar la existencia de diversas anomalías estructurales y funcionales en diversas regiones cerebrales. Habitualmente dichas regiones concuerdan con las «áreas del lenguaje» delimitadas mediante otros procedimientos (v. supra). Consecuentemente, también en este caso las áreas identificadas van a estar normalmente implicadas en tareas no relacionadas exclusivamente con el lenguaje, mientras que, de igual modo, su identidad, extensión y límites precisos difieren, hasta cierto punto, de un individuo afectado a otro. Significativamente, la disfunción de dichas áreas puede dar lugar en otros individuos a diferentes déficits y/o a trastornos de distinta naturaleza, incluyendo los de índole no lingüística. Así, por ejemplo, la disfunción de los ganglios basales, cuya importancia para el procesamiento lingüístico se apuntó anteriormente (v. también §6), no solo constituye la patología primaria en el subtipo de TEL asociado a la mutación del gen FOXP2 (Vargha-Khadem et al. 1998; v. infra), sino que es también el componente etiológico principal de otros trastornos que, en general, no revisten un carácter exclusivamente lingüístico, como la enfermedad de Huntington (Gusella y MacDonald 2006), la enfermedad de Parkinson (Duffy 2005), la 3- $\alpha$-metilglutaconicaciduria (Gibson et al. 1998), la glutaricacidemia de tipo I (Merinero et al. 1995) o la parálisis supranuclear progresiva (Goldman et al. 2005).

d) Finalmente, y a nivel genético, sucede frecuentemente que los genes que parecen constituir factores causales (o de riesgo) significativos para la aparición de esta clase de trastornos tampoco poseen un carácter exclusivamente lingüístico, toda vez que:

(i) se expresan en otras regiones cerebrales además de en las que intervienen en el procesamiento del lenguaje (esto es, lo hacen fuera de las «áreas del lenguaje», con todas las salvedades apuntadas anteriormente) e incluso en otros tejidos ajenos al sistema nervioso, y no solo durante la ontogenia, sino también en la etapa adulta, contribu- 
yendo presumiblemente a diversas funciones fisiológicas (un fenómeno conocido como "pleiotropismo»); así, por ejemplo, el anteriormente mencionado gen FOXP2, considerado como el «gen del lenguaje» por excelencia (Benítez Burraco 2009b, pp. 103-153; Fisher y Scharff 2009), se expresa durante el desarrollo embrionario en el pulmón, el intestino o el corazón, además de hacerlo en el cerebro (Shu et al. 2001), y lo hace también en diferentes tejidos del individuo adulto (Lai et al. 2001);

(ii) se encuentran en ocasiones mutados en individuos afectados por (a) trastornos del lenguaje diferentes, en términos clínicos, de aquellos a partir de los que fueron identificados inicialmente, o (b) trastornos cognitivos generales (esto es, no específicamente lingüísticos); en otros casos sucede que (c) se hallan simultáneamente ligados o asociados a más de un trastorno lingüístico (y/o cognitivo); así, por ejemplo, la mutación del gen $R O B O 1$, que codifica una proteína implicada aparentemente en la regulación del crecimiento de los axones (Hannula-Jouppi et al. 2005), se ha asociado tanto con la dislexia (Hannula-Jouppi et al. 2005) como con el SSD (Nopola-Hemmi et al. 2001);

(iii) en determinados individuos afectados por el trastorno su secuencia es normal (un fenómeno conocido como «fenocopia»);

(iv) en otros individuos la presencia de una variante mutada no afecta al normal desarrollo y funcionamiento de la FL «penetrancia nula» o solo hace de forma muy leve o, en todo caso, de modo menos acusado que en los casos típicos del trastorno "penetrancia reducida»;

(v) su identidad difiere (hasta cierto punto) de una población a otra y/o dependiendo del subtipo del trastorno, si bien en todos los casos el número de tales genes es sustancialmente elevado (un fenómeno conocido como "poligenismo») (para una revisión, v. Smith 2007; Benítez Burraco 2009b, pp. 240-28);

A lo anterior habría que añadir la paradójica circunstancia de que existe un número aún mayor de genes cuya mutación afecta simultáneamente al lenguaje (total o parcialmente) y a otras capacidades cognitivas, dando lugar a lo que en términos clínicos etiquetamos como trastornos del lenguaje inespecíficos (de carácter hereditario) o como trastornos cognitivos (de carácter hereditario) en los que el lenguaje se ve afectado (para una revisión, v. Benítez Burraco 2009b, pp. 88-94, 168-172, 177-227). Cabría preguntarse hasta qué punto estos otros genes 
están implicados en el desarrollo de la FL, en lugar de estarlo simplemente en el desarrollo del sustrato neuronal de dispositivos generales de aprendizaje, la cognición general, la inteligencia o dispositivos cognitivos implicados en la actuación. En $\S 6$ trataremos de justificar las razones por las que, de hecho, podrían estarlo realmente.

En conjunto, da la impresión de que este significativo cúmulo de evidencias que parece cuestionar el carácter específicamente lingüístico de los trastornos del lenguaje constituye un reto importante para cualquier modelo modular del lenguaje (y en particular, para el que es objeto de examen preferente en este trabajo). Así, al plantear la imposibilidad de relacionar, en todos los casos y de forma unívoca, dichos trastornos con déficits estrictamente lingüísticos, alteraciones estructurales y/o disfunciones de regiones cerebrales concretas (en principio, dedicadas de manera exclusiva al procesamiento de estímulos lingüísticos) o la mutación de determinados genes (que, en principio también, afectarían de forma exclusiva al desarrollo y al funcionamiento de dichas regiones), tales evidencias parecen negar a la FL propiedades fundamentales de los módulos cognitivos, al menos en su formulación original (cf. Fodor 1983) y tal como las recogen los modelos modulares más habituales desarrollados posteriormente (v. §1). Por lo demás, todas estas evidencias parecen sugerir, asimismo, la necesidad de identificar y considerar otros factores adicionales si se quiere explicar la emergencia del lenguaje (o de cualquier otro fenotipo cognitivo) al término del desarrollo, y de hecho, la propia dinámica seguida por la ontogenia de la FL (cf. Karmiloff-Smith 1998). Recordemos una vez más que, en su formulación más simple, nos enfrentamos a un paradójico escenario según el cual un determinado genotipo puede dar lugar a diversos fenotipos, mientras que en otras circunstancias distintas, diferentes genotipos pueden dar lugar al mismo fenotipo, sin que esté claro tampoco si la etiqueta «específicamente lingüístico» puede aplicarse lícitamente a alguno de ellos. Sea como fuere, el ambiente desempeñará, a buen seguro, un papel relevante en la modulación de tales procesos de desarrollo, como, por lo demás, parecía sugerir también otro nutrido corpus de evidencias, cuya importancia no cabe obviar ni minimizar. La naturaleza de dichas evidencias es, por una parte, cognitiva, como sucede con el importante papel desempeñado por los DLP en la consecución de la competencia gramatical del individuo adulto (v. § 2) o con la existencia de un período crítico para la emergencia del lenguaje (Schacter 1990; Lust 2006, p. 93). Pero por otra, es también neurobiológica, como sería el caso, por ejemplo, de la existencia de una plasticidad neuronal que permite responder estructural y funcionalmente a los cambios producidos en el ambiente, la cual no consiste en un simple mecanismo compensatorio de hipotéticos daños que afecten a la integridad de las estructuras neuronales, sino que es una propiedad in- 
trínseca de las mismas (Bates et al. 1992; Thomas et al. 1997; Kaufmann y Worley 1999; Deacon 2000; Hofmann 2003). Finalmente, dichas evidencias serían también genéticas. Así, dado que la célula no es un sistema aislado, la expresión de los genes estará condicionada por multitud de factores extracelulares, que no solo conciernen al ambiente externo, sino también a los restantes niveles de complejidad biológica que cabe distinguir en el sustrato neuronal del lenguaje, como tejidos, circuitos, áreas cerebrales, etc. (v. también $\$ 5$ ).

Para terminar, merece la pena detenerse a reflexionar, siquiera sea brevemente, acerca del particular empeño con que solemos tratar de correlacionar las posibles anomalías estructurales y funcionales detectadas a nivel cerebral por las técnicas de análisis a las que se hizo mención anteriormente (pero sobre todo, las representaciones visuales de las tareas computacionales que demandan los tests experimentales, tal como nos las proporcionan tales técnicas y cuando se aplican al análisis del procesamiento lingüístico en individuos sanos), con las funciones o componentes funcionales (o disfuncionales) del lenguaje. En general, tendemos a asumir que una correlación directa es posible, cuando en realidad, y como acertadamente sugieren Poeppel y Embick 2005, la Lingüística y la Neurobiología trabajan (por el momento) a dos niveles diferentes de resolución, de modo que la primera lo hace con entidades y procesos computacionales mucho más detallados que la segunda, que opera con distinciones conceptuales más básicas (por ejemplo, sintaxis/semántica en los trastornos afásicos). Simultáneamente, las diferencias existentes entre los respectivos elementos o unidades básicos de representación y los respectivos procesos de computación son (por el momento) de índole cualitativa, de manera que no pueden reducirse sin más los unos a los otros. Un corolario de lo anterior es, como también razonan Poeppel y Embick 2005, que la investigación neurobiológica del lenguaje no debe seguir teniendo como (único) objetivo la mera validación de (todos) los conceptos y categorías generados por la Lingüística teórica (en definitiva, la búsqueda a todo trance de sus correlatos biológicos, empeño que, a luz de lo discutido, se antoja especialmente problemático y cuestionable). Antes bien, su verdadero objetivo debería ser la propuesta de modelos de computación a nivel cerebral de los procesos y las (representaciones de las) categorías relevantes en términos lingüísticos que sean compatibles con la clase de computaciones que el cerebro es capaz de llevar a cabo en tiempo real. Surge entonces la pregunta de si los actuales modelos modulares de la FL constituyen un resultado de la primera forma de entender y abordar el análisis neurobiológico del lenguaje, o si a pesar de todo, la modularidad representa una etiqueta biológicamente plausible para un modelo neurobiológico del lenguaje que aspire a ser del segundo tipo. Como se discute en $\S 5$, el reanálisis de la hipótesis modular del lenguaje que plantea el 
presente trabajo tiene por objeto contribuir a satisfacer esa demanda de conseguir «the formulation of theoretically motivated, biologically grounded, and computationally explicit linking hypotheses that bridge neuroscience and linguistic» (Poeppel y Embick 2005). Por su parte, en $\S 6$ se discuten dos modelos concretos que podrían reclamar ese papel de puente entre ambas disciplinas. Y no podemos olvidar, por último, que «the forms of evidence on the language faculty that are provided by these [neurobiological] methodologies are just as relevant to linguistic theory as, say, native speaker intuitions are» (Poeppel y Embick 2005).

\section{REEVAlUANDO LA HIPÓTESIS MODULAR DEL LENGUAJE: ¿VINDICAR, DESCARTAR O REFORMULAR?}

Teniendo en cuenta la entidad de las evidencias discutidas en el apartado anterior, podríamos sentirnos tentados de negar directamente el carácter modular de la FL, proponiendo, en cambio, como lo hacen los modelos que suelen denominarse empiristas, que el lenguaje es el resultado de la actividad de dispositivos generales de procesamiento de información que actuarían sobre el input lingüístico. Dejaremos al margen las evidencias (psico) lingüísticas que parecen sugerir que la adquisición no es posible merced exclusivamente a un proceso de aprendizaje (en lo fundamental, de carácter estadístico, esté o no ayudado por la enseñanza o la imitación) (v. § 2 y Benítez Burraco 2008), y nos centraremos en los aspectos neurobiológicos del problema, que constituyen el genuino interés de este trabajo. Lo cierto es que también en este plano los modelos generalistas han de enfrentarse a problemas significativos. En particular, difícilmente pueden explicar el sustancial grado de estructuración que exhibe el cerebro en términos anatómicos, pero también funcionales, y no solo al final del desarrollo, sino durante la propia ontogenia, como evidencian:

(i) la persistencia y la repetibilidad de determinadas peculiaridades neuroanatómicas (Felleman y Van Essen 1991),

(ii) la existencia de patrones de activación cerebral sustancialmente semejantes en respuesta a tareas de procesamiento lingüístico de parecida naturaleza (para una revisión, v. Benítez Burraco 2005).

De hecho, lo que observamos desde un punto de vista neurobiológico durante las primeras etapas del desarrollo es que el cerebro tiende a alcanzar un significativo nivel de organización interna antes incluso de comenzar a procesar estímulos externos y consecuentemente, en ausencia de transmisión sináptica (Verhage et al. 2000; Bouwman et al. 
2004). Dicha estructuración implica el establecimiento de patrones básicos de interconexión entre diversos tipos de neuronas previamente diferenciados y, en último término, la delimitación de la organización fundamental del sustrato neuronal del lenguaje (Ramus 2006). No es menos cierto tampoco que este proceso, conocido como «anticipación ontogenética» (Balaban 2006, p. 317), no es capaz de generar por sí solo dispositivos computacionales plenamente operativos (Ramus 2006), que solo aparecen como consecuencia del efecto modulador ejercido por la propia actividad neuronal inherente al procesamiento lingüístico sobre las estructuras en desarrollo (se trata de un proceso eminentemente fisiológico, que comprende los cambios estructurales y funcionales experimentados por las neuronas como resultado de las interacciones que tienen lugar entre las diversas regiones cerebrales en desarrollo, y entre ellas y el ambiente). En definitiva, parece que las propiedades funcionales del cerebro surgen no solo como resultado de la interacción entre las diferentes poblaciones neuronales y de su competencia por ocuparse del procesamiento de determinados tipos de estímulos externos (Johnson 2003), sino también como consecuencia de un proceso de desarrollo y maduración de los centros neuronales (presumiblemente en respuesta a información innata, esto es, no derivable de la experiencia). Por lo demás, determinar el momento exacto en que comienza la experiencia no es en modo alguno sencillo (Gottlieb 1997). En todo caso, la pregunta fundamental sería, una vez más, si a la luz de todo lo anterior sigue teniendo sentido hablar de una FL modular.

Una forma de preservar la hipótesis modular ha consistido, sencillamente, en proponer, en la línea de lo observado durante el desarrollo, que la capacidad lingüística no dependería exclusivamente de circuitos prefijados desde el nacimiento, sino que existiría una cierta modularidad local, regulada genéticamente, que conviviría, sin embargo, con la presencia generalizada de patrones conectivos que tenderían siempre a organizarse de una manera semejante en respuesta a los estímulos externos (Deacon 2000, p. 280) y, desde luego, con una acusada capacidad de respuesta y de adaptación de la organización de dichos circuitos a los cambios producidos en el ambiente lingüístico que rodea al individuo. Sin embargo esto resulta excesivamente vago a la luz de los datos neurobiológicos disponibles actualmente.

Una hipótesis alternativa, plausible y francamente atractiva, supone la vindicación de una concepción eminentemente funcional de la modularidad (v. Barrett y Kurzban 2006, por ejemplo). Marcus 2006, por poner otro ejemplo, ha señalado acertadamente que dos módulos (cognitivos) pueden ser funcionalmente distintos (y de hecho, han de serlo para ser considerados como módulos), sin que tengan que ser independientes en términos genéticos, neurobiológicos o evolutivos (y de hecho, nunca lo son, como sugieren los datos discutidos en $§ 3$ ). Esto implica- 
ría que la mayor parte de los genes que intervienen en la regulación del desarrollo (y hasta cierto punto del funcionamiento) de las estructuras neuronales implicadas en el procesamiento lingüístico intervendrían también en el desarrollo del sustrato neuronal de otras capacidades cognitivas. Y lo mismo cabría afirmar de las propias estructuras resultantes de dicho desarrollo, que se encargarían de tareas computacionales no relacionadas exclusivamente con el lenguaje. Simultáneamente, sería lícito considerar como idiosincrásicos, y específicos del lenguaje, tanto el conjunto de factores genéticos implicados (en esencia, un grupo de genes relacionados funcionalmente con objeto de regular el desarrollo de determinadas estructuras neuronales involucradas en el procesamiento del lenguaje) como el de las propias estructuras neuronales (en esencia, un conjunto de circuitos/dispositivos interconectados entre sí para permitir las tareas computacionales que demanda dicho procesamiento). En otras palabras, una autonomía funcional a nivel cognitivo/fenotípico sería compatible con un significativo solapamiento a niveles biológicos más básicos. No obstante, y como se discute en $\S 5$, «función» es un término sustancialmente polisémico desde el punto de vista biológico, puesto que puede aludir indistintamente a la mera actividad desarrollada por una determinada estructura orgánica o al uso que se le da a dicha estructura como resultado de las conexiones que mantiene con otras estructuras diferentes (pero también como consecuencia de las relaciones existentes entre el organismo y su ambiente) (Love 2007). Por otro lado, tampoco parece quedar demasiado claro a qué nivel exacto cabría esperar disociaciones entre el lenguaje y la cognición, o incluso entre diferentes componentes del lenguaje, ni tampoco cuál sería el alcance de esas hipotéticas disociaciones.

En todo caso, es cierto que, en lo sustancial, una hipótesis como la anterior podría explicar las evidencias discutidas en $\S 3$ que parecían cuestionar el carácter modular de la FL y en particular, los paradójicos resultados derivados del análisis fenotípico/clínico, cognitivo, neuroanatómico, neurofisiológico y genético de los trastornos del lenguaje de carácter hereditario. Así, en un contexto pleiotrópico la mutación de un determinado gen puede afectar al normal desarrollo (y funcionamiento) de dos o más dispositivos neuronales diferentes, originando anomalías estructurales y funcionales que darán lugar a dos o más déficits distintos y consecuentemente, a síntomas diversos, susceptibles de categorizarse clínicamente como dos o más trastornos diferentes (en ocasiones heterogéneos y en ocasiones comórbidos). Sin embargo, como el contexto es simultáneamente poligénico, en ocasiones sucede que la mutación de dos o más genes funcionalmente relacionados da lugar a anomalías estructurales y funcionales semejantes en las mismas áreas cerebrales y por consiguiente, a un mismo déficit y a síntomas semejantes, que se categorizarán clínicamente como un mismo trastorno (que 
en ocasiones podrá ser heterogéneo). En otros casos, la mutación de este tipo de genes funcionalmente relacionados dará lugar, en cambio, a anomalías estructurales y funcionales en dos (o más) áreas cerebrales diferentes y por tanto, a déficits distintos, que, al manifestarse en forma de síntomas diferentes, serán categorizados clínicamente como trastornos distintos (en ocasiones heterogéneos y en ocasiones comórbidos). Crucialmente, y teniendo en cuenta todo lo discutido anteriormente, parece evidente que la regulación del desarrollo no depende únicamente de factores de naturaleza genética, sino que también lo hace de otros factores internos de índole dispar (pertenecientes a los distintos niveles de complejidad biológica que cabe distinguir en la FL), así como de factores externos (esto es, ambientales). Dichos factores afectan a la célula en que se expresan los genes, modulando en último término dicha expresión, lo que se traduce a menudo en la aparición de modificaciones epigenéticas del ADN (esto es, que no suponen una modificación de su secuencia, pero sí una alteración de la accesibilidad a la molécula de los factores implicados en su expresión). Adicionalmente, el desarrollo se ve también condicionado por los factores reguladores heredados por vía materna. Finalmente, diversos factores generales, de carácter fisicoquímico, condicionan de manera crucial la actuación de los restantes elementos reguladores implicados (proteínas, ARNs, hormonas, etc.), llegando a explicar dimensiones básicas de la organización de los tejidos en desarrollo. Es el caso, por ejemplo, de la viscoelasticidad, la difusión y la oscilación bioquímicas diferenciales, la dinámica de los gradientes de sedimentación y difusión, la excitabilidad mecanoquímica o las dimensiones del propio espacio en que transcurren las reacciones químicas, los cuales actúan en combinación con propiedades básicas de las células, como la polaridad y la adhesión diferencial (Newman y Comper 1990; Newman et al. 2006). Consecuentemente, y puesto que la contribución de cada producto génico disfuncional o afuncional al fenotipo final estará siempre (sutilmente) condicionada por el efecto debido al resto de factores reguladores del desarrollo implicados, en ocasiones sucederá también que la mutación de un mismo gen dará lugar en diferentes individuos a distintos grados de afectación de la integridad estructural o del normal funcionamiento de un determinado dispositivo neuronal y por consiguiente, a perfiles cognitivos y sintomáticos variables, susceptibles de categorizarse clínicamente como dos o más subtipos de un mismo trastorno o incluso, como dos o más trastornos diferentes (que en general serán comórbidos). En otros casos, en cambio, la mutación de dos genes diferentes originará en individuos distintos anomalías estructurales y funcionales en una misma área cerebral y, por tanto, un déficit común y síntomas semejantes, que se categorizarán clínicamente como el mismo trastorno (o como subtipos diferentes de un mismo trastorno). 
Cabe advertir, asimismo, que una hipótesis como la anterior preservaría, en lo sustancial, la disociabilidad en términos fenotípicos de la FL con respecto a otras capacidades cognitivas, pero admitiendo simultáneamente la existencia de numerosos elementos comunes a todas ellas a diferentes niveles de complejidad biológica. Consecuentemente, cabe argüir que preservaría igualmente la propia hipótesis modular, aunque sometida a significativas modificaciones. Antes de discutir las características de posibles modelos concretos de la FL acordes con esta nueva variante de la hipótesis (v. §6), es necesario abordar el importante reto adicional que parece plantear a los modelos modulares (e incluso a esta versión modificada de la hipótesis modular) el análisis de la ontogenia de los trastornos del lenguaje ligados al desarrollo (y en general, de los trastornos cognitivos de carácter hereditario en los que el lenguaje se ve afectado en alguna medida). Ello nos obligará a reexaminar una vez más dicha hipótesis, esta vez a la luz de los presupuestos teóricos de la biología del desarrollo evolutiva (v. \$5). Lo cierto es que, al margen de la variabilidad observada en términos fenotípicos en el estadio adulto entre los individuos que manifiestan una misma alteración genética (y de las diferencias que, claro está, puedan mantener a este respecto con la población normal), el perfil lingüístico de este tipo de trastornos suele cambiar también significativamente a lo largo del desarrollo. En otras palabras, el grado de afectación de la competencia lingüística va variando durante la ontogenia, de modo que una descripción del proceso en términos de «lenguaje afectado/lenguaje preservado» resultaría excesivamente simplista. Suele suceder además que dicho itinerario ontogenético se aparta, asimismo, del que es característico de la población que no presenta el trastorno. En parte, este complejo escenario podría explicarse en virtud del modo en que los genes (y el resto de los factores implicados) contribuyen a la regulación del desarrollo y el funcionamiento de las estructuras neuronales, y en virtud también de los fenómenos concomitantes a dicha contribución (pleiotropismo, epigénesis, poligenismo, etc.), tal como se discutieron anteriormente. Sin embargo, a la luz del modo en que evoluciona dicho perfil lingüístico (v. infra) y de la manera en que tiene lugar realmente el desarrollo cerebral (v. supra), cabe preguntarse si dicha explicación es suficiente, o si por el contrario, aquella variabilidad responde también a una alteración del complejo patrón de interacción que tiene lugar entre las distintas regiones cerebrales (y entre estas y el ambiente) a lo largo del desarrollo (cf. Johnson 2003). Una vez más: ¿es compatible (y hasta qué punto lo sería) este escenario con la hipótesis modular?

Un caso paradigmático a este respecto ( $\mathrm{y}$ al mismo tiempo, un ejemplo manifiesto de la complejidad del problema al que nos enfrentamos) lo constituye el denominado síndrome de Williams-Beuren, un trastorno cognitivo ligado a la hemicigosis de una veintena de genes causada 
por una microdeleción que afecta a una de las copias del cromosoma 7 (Korenberg et al. 2008). Tradicionalmente este síndrome se ha presentado como un caso de disociación inversa entre la cognición general y el lenguaje, de manera que la primera (fundamentalmente la de tipo visuoespacial) se hallaría significativamente afectada, mientras que el segundo se encontraría intacto (Bellugi et al. 1999). Asimismo, se ha defendido que a lo largo del desarrollo los diferentes dominios cognitivos (por ejemplo, conocimiento léxico, cognición espacial y reconocimiento visual en Jones et al. 1998) seguirían trayectorias distintas, de modo que unos se verían preservados y otros alterados, lo que no solo justificaría una organización modular estricta de la cognición (y del lenguaje), sino un desarrollo cognitivo (y una ontogenia lingüística) que en lo fundamental progresaría merced a la maduración de dispositivos autónomos, siempre intactos o siempre deficitarios. Ahora bien, como cabría esperar de lo discutido en $\S 3$ en relación con los trastornos del lenguaje (supuestamente específicos), un análisis detallado de su actuación parece sugerir que los individuos adultos aquejados por este síndrome presentan en realidad diversos déficits de índole lingüística, que afectan a todos los niveles del lenguaje y que se manifiestan, entre otros aspectos, en:

(i) un lexicón empobrecido en términos que denotan relaciones o conceptos abstractos (en comparación con su riqueza en términos que denotan referentes concretos),

(ii) una elección incorrecta de complementadores,

(iii) una mayor frecuencia de errores en el uso de las preposiciones espaciales y de los deícticos,

(iv) la supresión ocasional de marcas de tiempo verbal, auxiliares y cláusulas subordinadas obligatorias,

(v) un déficit de procesamiento de estructuras sintácticas complejas (paradigmáticamente, cláusulas de relativo incrustadas, e incluso en tareas de repetición),

(vi) determinados problemas de concordancia,

(vii) problemas diversos de comprensión, y

(viii) anomalías en el uso pragmático del lenguaje (Karmiloff-Smith 2006; Mervis y Becerra 2007; Martens et al. 2008, y las citas allí recogidas).

No obstante, no es menos cierto que la competencia gramatical finalmente alcanzada por estos individuos supera, en apariencia, a la que es habitual en otros trastornos ligados al desarrollo (en particular, en el síndrome de Down, que se ha empleado tradicionalmente como control en este tipo de estudios) y resulta particularmente llamativa a la luz de los importantes déficits que presentan los afectados por el síndrome 
en otros dominios cognitivos (paradigmáticamente, en el procesamiento de información visual de carácter espacial). Simultáneamente, dicha competencia no supera a la que cabría esperar en atención a su edad mental (Karmiloff-Smith 2006; Karmiloff-Smith 2008). A primera vista, lo que parece suceder es que el nivel cognitivo alcanzado por estos sujetos al final de su desarrollo, que se asemeja en términos globales al de un niño de entre cinco y siete años, podría ser suficiente para garantizar un desarrollo más o menos normal del lenguaje, aunque incompleto en ciertos dominios específicos. Como resulta evidente, la pregunta crucial a este respecto es si nos encontramos realmente ante una FL intacta, y en qué medida y a qué nivel lo estaría.

Dos circunstancias adicionales revelan la dimensión real del problema al que nos enfrentamos y nos sitúan ante un escenario a priori inesperado. Por un lado, da la impresión de que los meros datos derivados del análisis de la actuación resultan insuficientes (y en este caso particular, engañosos) si se pretende determinar la genuina naturaleza (y el verdadero alcance) de los déficits lingüísticos presentes en estos individuos. Así, por ejemplo, en lo concerniente al procesamiento de las oraciones, se advierte sistemáticamente que la información semántica se vuelve disponible con excesiva lentitud como para poder ser adecuadamente integrada con la sintáctica en tiempo real (Karmiloff-Smith $e t$ al. 1998). Simultáneamente, la información fonológica desempeña un papel más importante de lo normal en este tipo de tareas. Finalmente, se observa también una correlación mayor de lo habitual entre la memoria de trabajo verbal y las capacidades gramaticales. En conjunto, da la impresión de que la excelente memoria de trabajo verbal que poseen los individuos afectados por el síndrome enmascara déficits de índole morfosintáctica, semántica y pragmática que revisten una mayor entidad de lo que deja traslucir su actuación, que puede llegar a resultar casi normal (Mervis y Becerra 2007). Como acertadamente señalan Donnai y Karmiloff-Smith 2000, p. 167 «sometimes equivalent behavioral scores camouflage very different cognitive processes». Así pues, si una actuación lingüística casi normal puede ser el resultado de la interacción de procesos cognitivos que se hallan significativamente afectados, o que pueden ser incluso cualitativamente diferentes en relación con los que intervienen en el procesamiento lingüístico en la población normal, parece evidente que «to understand any developmental syndrome, it is essential to distinguish between the behavioral phenotype (based on scores from standardized tests of overt behavior) and the cognitive phenotype (based on in-depth analyses of the mental processes underlying the overt behavior)» (Donnai y Karmiloff-Smith 2000, p. 167; v. Karmiloff-Smith 1998). Esta necesidad introduce, por consiguiente, un nivel adicional de complejidad en lo que hasta el momento veníamos considerando como «módulo funcional» sin más. Por lo demás, y como también cabría es- 
perar, a nivel neurobiológico se observan igualmente diferencias significativas, en términos de estructura y actividad cerebrales, entre los individuos afectados por el síndrome de Williams y los no afectados. Así, por ejemplo, en los primeros se advierte una mayor asimetría del plano temporal (Hickok et al. 1995), así como un mayor tamaño de la circunvolución temporal superior y del volumen del neocerebelo (Bellugi et al. 1999); simultáneamente, en diversas áreas cerebrales las células se organizan según patrones anómalos (Martens et al. 2008 y las citas allí recogidas). Desde el punto de vista neurofisiológico se detecta, en particular, la generación de picos anormalmente altos del componente P200 en respuesta a la recepción de elementos léxicos discretos (Bellugi et al. 2001), mientras que está ausente el patrón diferencial en los ERPs que caracteriza a las categorías funcionales y de contenido léxico (Bellugi et al. 1999; St. George et al. 2000). En suma, la entidad de las anomalías observadas a nivel neurobiológico parecen predecir también un mayor nivel de afectación de las capacidades lingüísticas que lo que deja traslucir la actuación. Consecuentemente, no parece que las anomalías de todo tipo (neuroestructurales, neurofuncionales, cognitivas) observadas en el síndrome de Williams puedan describirse, sin más, como una mera yuxtaposición entre módulos intactos y otros afectados (cf. Karmiloff-Smith 2003).

Pero lo que reviste una importancia aún mayor es, en la línea de lo apuntado anteriormente, que en este síndrome el perfil cognitivo y el perfil lingüístico de los niños difiere significativamente del que manifiestan los adultos -de forma que la actuación de los primeros se halla disminuida en mayor medida que la de los segundos, normalizándose progresivamente conforme van creciendo (Paterson et al. 1999), aunque con todas las salvedades indicadas anteriormente-, y sobre todo, que, en conjunto, la ontogenia lingüística de los afectados presenta importantes diferencias, de índole cronológica, cuantitativa y acaso cualitativa, con la que es característica en la población normal. Así, en particular, el comienzo del desarrollo lingüístico se halla significativamente retrasado, lo que afecta específicamente al momento de aparición de componentes relevantes del habla, como las curvas melódicas o el balbuceo. Asimismo, se advierte una mayor variabilidad en las características de determinados aspectos del proceso de adquisición, como ocurre con la estructura del balbuceo canónico. Por último, se observan también diferencias significativas, como una mayor sensibilidad a los patrones sonoros del habla en relación con su posible significado (¿cabría pensar que en estos individuos el proceso de adquisición se apoya en mayor medida de lo habitual en el arranque prosódico/fonológico?). Por su parte, en el plano gramatical, resulta llamativa la mayor persistencia de los errores morfológicos a lo largo del desarrollo (en forma, por ejemplo, de un exceso de variantes sobrerregularizadas en la morfología 
verbal), de modo que el patrón de adquisición, aunque semejante al normal en términos cualitativos, se ve retrasado en el tiempo (¿cabría pensar que en estos individuos el proceso de adquisición está sujeto a restricciones diferentes?). Finalmente, las anomalías observadas en el plano semántico se antojan especialmente significativas. Así, se advierte un retraso generalizado del proceso de adquisición de la competencia semántica (de modo que, por ejemplo, la barrera de las cien palabras no se alcanza, de media, hasta los 40 meses de vida, cuando en la población normal se supera, en promedio, a los 18 meses) y, específicamente, de capacidades básicas para el procesamiento semántico (por ejemplo, la capacidad de establecer correspondencias rápidas solo se documenta a partir de los 48 meses). Asimismo, se observa también la presencia de dificultades para llevar a cabo tareas específicas (paradigmáticamente, la categorización y la extensión semánticas, de modo que las semejanzas entre las palabras se reconocen a nivel perceptivo, pero no lingüístico) o para usar adecuadamente términos concretos (típicamente, palabras que denotan conceptos espaciales, pero en general, términos relacionales de todo tipo). Especialmente significativa resulta, por último, la alteración observada en el curso habitual de aparición de algunos de los hitos que señalan la consecución del proceso de adquisición del componente semántico (de manera que, por ejemplo, el uso de términos referenciales precede a la capacidad de señalar gestualmente y de seguir visualmente este tipo de gestos) o incluso la detención de determinados aspectos de este proceso, como ocurre con la organización semántica del lexicón, que, si bien parece normal a nivel local (en términos de priming effects y de fluidez categorial), nunca alcanza en términos globales la que es característica del estadio final de desarrollo de la población no afectada por el trastorno y ello con independencia de la eficiencia comunicativa lograda por el individuo. Se ha llegado a sugerir que existiría incluso una desviación de dicho proceso organizativo, de modo que el lexicón se enriquecería a partir de cierta edad en términos concretos poco frecuentes, ligados a los intereses particulares del individuo (para una revisión de la ontogenia lingüística del síndrome de Williams y en particular, de las anomalías señaladas anteriormente, v. Karmiloff-Smith 2006; Mervis y Becerra 2007; Karmiloff-Smith 2008; Martens et al. 2008).

Por lo demás, también en términos neuroanatómicos y neurofisiológicos se observa en este síndrome un itinerario de desarrollo anómalo, de modo que, por ejemplo, el patrón electrofisiológico en respuesta al procesamiento de elementos semánticos es el normal hasta los tres o cuatro años de edad, volviéndose anómalo, en el sentido descrito anteriormente, solo a partir de ese momento (Mills et al. 2003). Como acertadamente resume Karmiloff-Smith 2006, p. 587, «there is in W[illiams] $\mathrm{S}$ [yndrome] a mixture of delay, deviance, and asynchronies across the developing system». Una vez más, cabe preguntarse si una hipótesis mo- 
dular del lenguaje es compatible con este complejo escenario, máxime cuando da la impresión de que «the static notions of intactness and of selective dissociations [would need] to be replaced with a developmental notion of 'atypically developing trajectories' over time» (Karmiloff-Smith 2006, p. 585), si nuestra intención última es la de comprender «why the language of people with WS language is initially so delayed and why, despite this, they develop surprising proficiency by adulthood compared to many other genetic syndromes with equal delay in early development» (Karmiloff-Smith 2006, p. 587). Resulta evidente que la respuesta debe encontrarse en el modo en que transcurren los procesos de desarrollo.

\section{LA HIPÓTESIS MODULAR DEL LENGUAJE A LA LUZ DE LA BIOLOGÍA DEL DESARROLLO EVOLUTIVA (EVO-DEVO)}

Una conclusión como la que cierra el apartado anterior nos enfrenta, a pesar de todo, a diferentes escenarios posibles. Así, por ejemplo, en los modelos denominados emergentistas (o constructivistas) la estructura cerebral (y en último término, la existencia de dispositivos funcionalmente independientes, esto es, de módulos) es, ciertamente, el resultado de un proceso de desarrollo, si bien en el sentido fundamental de ser una consecuencia de la interacción entre diversos sistemas generales de procesamiento descentralizados, y entre estos y el medio externo (Buller 2005; Elman et al. 1996; Smith y Thelen 2003). Dicho de otro modo, los hipotéticos módulos observados en el estadio adulto se describen necesariamente (y en muchos casos, exclusivamente) como un producto de dicho desarrollo (Karmiloff-Smith 1992; Paterson et al. 1999), sin que tenga sentido hablar de ellos al comienzo de la ontogenia. Como sugieren aforísticamente Bates et al. 1988, p. 284, «modules are not born; they are made». Sin embargo, una concepción del desarrollo como la anterior difícilmente sería capaz de explicar un fenómeno como la anticipación ontogenética (v. §4). Una vez más, parece un error presentar esta clase de hipótesis y modelos como opuesta a (o directamente incompatible con) la que representan las hipótesis y los modelos caracterizados habitualmente como innatistas. En realidad, vindicar un papel más relevante para los procesos de interconexión intrarregionales e interregionales (en respuesta a estímulos externos) en la configuración funcional del cerebro puede ser perfectamente compatible con la posibilidad de que su desarrollo estructural y funcional esté regulado, asimismo, por factores internos (en principio, no derivables de la experiencia y por consiguiente, innatos) y en particular, con que dichos factores sean (parcialmente) responsables de la aparición de los posibles dispositivos de procesamiento autónomos que observamos al término del desarrollo. De hecho, en $\S 4$ planteamos que, a la luz de las evidencias 
derivadas del estudio de los trastornos del lenguaje ligados al desarrollo, resulta lícito postular la existencia de un conjunto de genes que contribuyen de forma coordinada a regular el desarrollo del sustrato neuronal de la FL. A su vez, dicho sustrato estaría integrado por grupos de neuronas que actuarían de forma coordinada para permitir el procesamiento lingüístico y cuyo output sería lo que fenotípicamente describimos como "competencia», FL o simplemente lenguaje, en esencia, y dejando al margen el hecho de que estas etiquetas identifican entidades substancialmente diferentes, "one component of the human mind» (Chomsky 1977, p. 164). Y ello, a pesar de que tanto cada uno de los genes implicados, como cada una de las áreas cerebrales que intervienen en el procesamiento del lenguaje serían, en su mayoría, compartidos con otras capacidades cognitivas. El verdadero reto estriba, por consiguiente, en tratar de ligar el itinerario ontogenético del sustrato neuronal de la FL con su organización estructural en el individuo adulto y con el tipo de procesos que lleva a cabo, y en último término, con la función cognitiva que satisface. En modo alguno es un reto menor, pero la pregunta que debemos plantearnos en relación con los objetivos de este trabajo es, una vez más, si llegados a este punto existen niveles de complejidad biológica de la FL (pero también qué niveles serían estos) en relación con los cuales quepa considerar la modularidad como un concepto apropiado para describir lo que observamos en ellos y, consecuentemente, a qué nivel (o niveles) es también conveniente u obligado prescindir de la hipótesis modular.

La respuesta que daremos a esta pregunta pasará por recurrir (y explorar las implicaciones inherentes) al concepto de módulo con el que trabaja la moderna biología del desarrollo evolutiva (evo-devo). En este paradigma -puesto que aún no existe ninguna teoría unificada de evo-devo (Hall y Olson 2003, p. xv) - un módulo es, en esencia, cualquier conjunto de elementos que presenta un alto grado de cohesión interna, merced a la existencia de interacciones numerosas y robustas entre sus elementos constituyentes, y un bajo grado de cohesión con otros conjuntos equivalentes (esto es con otros módulos), con los que mantiene interacciones más débiles y menos frecuentes (Wagner 1996; Wagner y Altenberg 1996; Kirschner y Gerhart 1998). Consecuentemente, aquel conjunto de genes interrelacionados funcionalmente puede considerarse lícitamente como un módulo (genético), de la misma manera que aquel conjunto de poblaciones neuronales interconectadas funcionalmente también podría considerarse un módulo (neurobiológico). En realidad, la modularidad aflora como una propiedad fundamental de todos los sistemas biológicos a cualquier nivel de complejidad organizativa, a los que confiere simultáneamente robustez (esto es, insensibilidad a las perturbaciones externas; cf. Kitano 2004) y flexibilidad (es decir, capacidad de responder a dichas perturbaciones; cf. Bergman y 
Siegal 2002). Siendo así, la modularidad debe ser también indispensable para comprender la estructura y el funcionamiento de la mente (Barrett y Kurzban 2006) y por inclusión, la genuina naturaleza del lenguaje.

Ahora bien, en evo-devo se establece una dicotomía básica entre «módulo ontogenético» (en esencia, un conjunto de interacciones coordinadas entre los factores reguladores responsables del desarrollo de una determinada estructura biológica, que a su vez desempeña una determinada actividad) y «módulo funcional» -en esencia, una unidad resultante de la integración de ciertos rasgos (en lo fundamental, varias de tales estructuras biológicas) que satisfacen una determinada función(Breuker et al. 2006). Antes de proseguir, es conveniente realizar dos precisiones importantes. La primera es que, en atención a lo discutido en $\S 4$ acerca de la naturaleza y el modo de actuación de tales factores reguladores, y en general, de la manera en que tienen lugar los procesos de desarrollo, conviene dejar de lado la idea de que los módulos ontogenéticos equivalen necesariamente a genetic toolkits, es decir, conjuntos de genes que actúan de forma coordinada regulando cada etapa de la ontogenia y que conformarían programas de desarrollo preestablecidos y almacenados en el genoma que se pondrían en marcha en respuesta a los estímulos ambientales (cf. Rosenberg 1997; Maynard Smith 2000; True y Carroll 2002; Carroll 2005). Antes bien, todos los factores reguladores implicados actúan en términos de paridad, en el sentido de que todos son igualmente indispensables para la consecución del fenotipo final (Oyama 1985; Oyama et al. 2001; Griffiths y Gray 2004). Adviértase además que, dado que todos ellos aparecen y actúan recurrentemente en determinadas etapas del desarrollo, todos pueden considerarse legítimamente innatos (v. Bateson y Mamelli 2007). La segunda precisión, relacionada esta vez con el concepto de módulo funcional, concierne a la reflexión que también hacíamos en $\S 4$ acerca de los posibles significados del término «función» en Biología: en este caso, se está haciendo referencia al segundo de ellos, esto es, al uso dado a una estructura biológica como resultado de las conexiones que mantiene con otras estructuras y con el ambiente (Love 2007).

Teniendo presentes ambas precisiones, lo genuinamente importante en relación con la dicotomía «módulo ontogenético/módulo funcional» son, como también discuten Breuker et al. 2006, las diversas evidencias que parecen cuestionar la validez universal (y el carácter obligatorio) de la denominada «hipótesis del solapamiento», según la cual los módulos ontogenéticos evolucionarían adaptativamente para coincidir con los módulos funcionales (Wagner y Altenberg 1996). Por el contrario, determinados módulos funcionales pueden ser el resultado de las actividades llevadas a cabo de forma coordinada por dos (o más) estructuras biológicas, las cuales serán a su vez el producto de dos (o más) módulos ontogenéticos, que actuarían realmente como restricciones 
ontogenéticas a ulteriores cambios evolutivos -es decir, favoreciendo o desfavoreciendo (o si se quiere, canalizando) determinadas trayectorias de desarrollo- (Raff 1996). Así, por ejemplo, el escutelo y el ala de un escarabajo constituyen dos módulos ontogenéticos diferentes; simultáneamente, el primero y la porción basal de la segunda conforman un único módulo funcional, destinado a proteger el cuerpo del animal (Breuker et al. 2006). En último término, lo anterior sugiere que la relación entre el desarrollo estructural y la emergencia de funciones nuevas no es tan directa como cabría suponer en una primera instancia, de manera que determinadas funciones pueden surgir sin necesidad de que se produzcan modificaciones sustanciales en los dispositivos (eminentemente genéticos) que intervienen en la regulación del desarrollo.

La clasificación triádica de Winther 2001 profundiza en la compleja relación existente entre los diversos tipos de módulos y trae a primer plano lo apuntado previamente acerca del valor polisémico del término «función» en Biología. Así, este autor distingue (pp. 117-118) entre «módulos ontogenéticos» ( «parts that are conceptualized as changing over ontogenetic time»), «estructurales» («parts that compose an organism at a time-slice of ontogeny, typically the adult stage») y «fisiológicos» («modules $[\ldots]$ individuated by their activity $[\ldots]$ in adults»), señalando que las funciones biológicas pueden ser llevadas a cabo por diversos módulos (estructurales) y que un mismo módulo puede desempeñar varias, una o ninguna función biológica (siempre en la segunda acepción del término discutida anteriormente), puesto que «functions are selective or analytical reasons for [...] processes» y que «a process may not have a function». Finalmente, y centrándonos ya en el caso particular de la cognición, Griffiths 2007 discute la conveniencia de distinguir entre tres tipos diferentes de módulos: «ontogenéticos», «(neuro)funcionales»y «mentales (o virtuales)». La diferencia entre los dos últimos estribaría en que mientras que los módulos (neuro)funcionales corresponderían a estructuras neuronales encargadas de actividades específicas, distinguibles y separables de otras equivalentes, los mentales equivaldrían, en cambio, a patrones de disociación entre los sistemas de actuación que no se corresponderían, sin embargo, con la existencia de sistemas neuronales separados, si bien aprehenderían aquellos «aspects of an organism's psychological performance profile that can be developmentally and functionally dissociated from one another in such a way as to allow performance in one domain to be optimized independently of performance in the other» (Griffiths 2007, p. 216). El lenguaje podría ser uno de estos aspectos.

Dejaremos de lado las posibles disputas de índole terminológica (y acaso conceptual) que puedan plantearse en relación con este tipo de clasificaciones (por ejemplo, el concepto de función al que aluden Breuker y otros parece ser diferente del que utiliza Griffiths, aunque ambos re- 
miten, en realidad, a las dos acepciones posibles del término discutidas por Love 2007). Haremos también lo propio con la previsible discusión acerca de si los diversos módulos constituyen respuestas a problemas adaptativos diferentes (aunque v. Sterelny y Griffiths 1999, pp. 328-332 a este respecto). Es esta, con todo, una cuestión que no deja de ser relevante en el contexto que nos ocupa, toda vez que los modelos chomskyanos de la FL han sido considerados tradicionalmente como antiadaptacionistas (v. Lorenzo 2009 para una discusión). Y sin embargo, parece, a la luz de lo discutido anteriormente, que las innovaciones evolutivas (como sería el caso del lenguaje) pueden surgir también en condiciones de neutralidad (esto es, sin necesidad de responder a necesidades adaptativas concretas), precisamente como consecuencia de la dinámica y de las propiedades generativas de los sistemas de desarrollo (Müller y Newman 2005), de modo que solo posteriormente serían sancionadas por la selección natural (Müller 2007). En todo caso, y como hemos indicado ya en diversas ocasiones, lo que nos interesa realmente es encontrar un modo de relacionar el itinerario ontogenético del sustrato neuronal de la FL con su organización estructural al término del desarrollo y con el tipo de procesos que es capaz de realizar, y en último extremo, con la función cognitiva que satisface. Y recordemos también que buscamos hacerlo sin tener que renunciar a la modularidad como un descriptor básico del modo en que se organizan y tienen lugar los procesos relacionados con el lenguaje a todos esos niveles. Pues bien, los conceptos de «módulo ontogenético», «módulo (neuro)funcional» $\mathrm{y}$ «módulo mental» anteriormente discutidos podrían servirnos para lograrlo. Así, durante el desarrollo, el cerebro embrionario sería un mosaico de diversos módulos ontogenéticos (adviértase, una vez más, que los genes, que tanta importancia tienen en la controversia innatismo/emergentismo solo representarían uno de los diversos factores reguladores implicados), los cuales darían lugar a diversas estructuras neuronales que llevarían a cabo actividades concretas (en definitiva, a módulos estructurales/fisiológicos). A su vez, dichas estructuras se interconectarían entre sí en respuesta a los diversos factores reguladores del desarrollo (un proceso que podría caracterizarse lícitamente en términos de anticipación ontogenética), anticipando posibles dispositivos funcionales, si bien los dispositivos plenamente operativos (módulos [neuro]funcionales) solo aparecerían bajo la influencia de factores externos adicionales, dando lugar a nuevos cambios estructurales y funcionales en las neuronas. En ciertos casos estas entidades podrían disociarse de otras parecidas en términos de actuación, esto es, atendiendo a los resultados derivados de las tareas computacionales que son capaces de llevar a cabo (módulos mentales o virtuales). Sin embargo, en ningún caso lo serían en términos genéticos o neurobiológicos. En realidad, y como acertadamente señala Griffiths 2007, p. 202, «a modu- 
larity concept that simply identified a module with a neural system that produces double dissociations would not be useful for neuropsychology because it would serve only to blur distinctions between different neural architectures».

\section{Modelos de LA FL EN CONSONANCiA CON UNA (NUEVA) HiPÓtesis MODULAR}

Para el lingüista, lo verdaderamente relevante es si cabe proponer modelos de la FL que casen con el escenario descrito en $\$ 5$. La respuesta es, en principio, afirmativa.

Lieberman 2000; 2002; 2006, por ejemplo, ha desarrollado un modelo neurolingüístico, conocido como «gramática de los ganglios basales», según el cual la FL equivale, en esencia, a un sistema computacional capaz de procesar elementos simbólicos y de lograr la exteriorización y la interiorización del resultado de las computaciones que lleva a cabo en forma de secuencias de sonidos. Para Lieberman, este sistema computacional es el resultado de la interacción entre un secuenciador (la actividad que llevan a cabo los ganglios basales) y una memoria de trabajo (el resultado de las actividades coordinadas que desempeñan diversas estructuras corticales). Significativamente, un sistema computacional de este tipo podría aplicarse al procesamiento de inputs de diversa naturaleza y no solo de los elementos almacenados en el lexicón, de modo que sería capaz igualmente de generar secuencias motoras (recordemos que en $\$ 3$ discutimos que la alteración de los ganglios basales origina habitualmente trastornos del lenguaje y de la cognición que suelen ir acompañados de una disfunción motora). Consecuentemente, lo que Chomsky denominaba «one component of the human mind» sería el resultado de la interacción entre diferentes módulos funcionales (à la Griffiths), los cuales serían, a su vez, el producto de distintos módulos ontogenéticos, sin que exista una relación unívoca entre ellos (este escenario es también del máximo interés en términos evolutivos, tal como discuten Balari y Lorenzo 2008-2009, y Balari et al. en prensa).

La hipótesis que venimos desarrollando proporcionaría, asimismo, un soporte biológico a otros modelos de la FL aparecidos en el campo de la Lingüística, en particular, al emanado del Programa Minimalista chomskyano (Chomsky 2000a; Hauser et al. 2002; Chomsky 2005; Lorenzo 2009). Como se apuntó en $§ 1$, el Programa Minimalista implica, entre otras cosas, el abandono de la idea de la existencia de una GU, una decisión que parece verse refrendada por las evidencias de carácter genético y neurobiológico discutidas en $\S 3$. La FL se concibe ahora como una interfaz entre los sistemas cognitivos responsables del pensamiento y los sistemas sensorimotores implicados en la percepción y la motrici- 
dad (conocidos habitualmente como «externos»). En un trabajo muy conocido (Hauser et al. 2002), Chomsky plantea una distinción fundamental entre lo que llama FL en sentido estricto (FLE) (en esencia, un sistema computacional capaz de un procesamiento recursivo) y lo que denomina FL en sentido amplio (FLA) (en esencia, todos los aspectos relacionados con los contenidos que se van a expresar e interpretar, así como con las señales empleadas para su transmisión). Sin embargo, según la tesis minimalista más fuerte (Chomsky 2000b, p. 96), la versión óptima de la FL sería, de hecho, aquella que implicase un mínimo de maquinaria gramatical, hasta el extremo de que la FL emergería de forma obligada durante el desarrollo como resultado del acoplamiento directo entre los sistemas externos, siempre que el crecimiento tuviera lugar en presencia de un umbral de estímulos lingüísticos (Hauser et al. 2002). Hasta cierto punto, el proceso (aunque también el propio funcionamiento de la FL) dependería, asimismo, de las leyes generales que regulan la organización de los sistemas biológicos -lo que Chomsky ha llamado el «tercer factor» (Chomsky 2001, pp. 1-2; 2005)-. En este contexto, los principios gramaticales específicos (derivados, en los modelos preminimalistas, de instrucciones genéticas) se volverían innecesarios. Como cabe colegir, el Programa Minimalista posee implicaciones muy importantes en relación con la cuestión que estamos tratando. Tal como las formulan Longa y Lorenzo 2008, cabría mencionar las siguientes:

(i) vindica la inespecificidad de los principios que constituyen la FL,

(ii) relativiza tanto el carácter modular de la FL como su modularidad interna, de modo que la FL quedaría reducida a una distinción mínima entre el lexicón y un sistema computacional; y

(iii) defiende un modelo «disposicional» de adquisición del lenguaje, en el sentido de que la FL sería meramente el resultado obligado de la interacción de los sistemas externos durante el desarrollo (una vez más, en presencia de un umbral de estímulos lingüísticos y dependiendo en buena medida de aquellas leyes generales de organización de los sistemas biológicos).

Teniendo en cuenta todo lo discutido en este trabajo, cabría sugerir un modo en que podría implementarse biológicamente una hipótesis como la anterior, que fuese simultáneamente compatible con el concepto ampliado de modularidad tratado en $\$ 5$ y con la necesidad de que ciertos aspectos de la FL se siguieran derivando de principios específicos de dominio, y en último término, con la propia hipótesis innatista (v. Lorenzo y Longa 2008). Así, si se acepta la validez de una caracterización de la FL en términos de una FLE y una FLA, la FLE podría consistir en un sistema computacional recursivo (o más exactamente, de régimen 1 en la Jerarquía de Chomsky 1956; 1959) susceptible de acoplarse fun- 
cionalmente a diferentes dispositivos cognitivos y sensorimotores (y rendir, de este modo, diversos tipos de outputs), cuyo sustrato neuronal podría corresponderse con el propuesto por Lieberman. Se trataría, en lo fundamental, y siguiendo la terminología de Griffiths 2007 de un módulo (neuro)funcional, resultante a su vez de varios módulos ontogenéticos (en particular, los que originan los ganglios basales y las diversas estructuras corticales que conforman el sustrato de la memoria de trabajo del procesador). Al acoplarse a tales dispositivos cognitivos y sensorimotores, se generaría una entidad disociable, en términos de actuación, de otras de semejante naturaleza (que serían consecuencia, a su vez, del acoplamiento funcional de dicho procesador a otros dispositivos diferentes, o bien, de otros módulos [neuro]funcionales entre sí), en definitiva, el módulo mental o virtual que denominamos FLA. Bajo la hipótesis minimalista más fuerte, la FL sería el resultado de la interacción directa entre los sistemas externos, o si se quiere, entre diversos módulos (neuro)funcionales preexistentes, siendo al mismo tiempo una entidad autónoma desde el punto de vista cognitivo (o si se quiere, un módulo mental o virtual).

Por lo demás, la aparición de este tipo de módulos (mentales, en la caracterización de Griffiths, o funcionales, si se opta por la de Breuker et al.) sería el resultado (siempre que el ambiente ontogenético reúna los mínimos requisitos para ello) de la propia dinámica seguida por el proceso de desarrollo del organismo, que, en esencia, descansa precisamente en la organización modular de los sistemas biológicos a todos los niveles de complejidad. De este modo, la FL no sería el producto directo de ningún módulo ontogenético stricto sensu, sino el resultado del acoplamiento funcional durante el crecimiento de estructuras autónomas (en términos anatómicos y fisiológicos, esto es, desde el punto de vista de su organización y de la actividad que realizan) desarrolladas de modo casi independiente (en definitiva, de uno o varios módulos [neuro]funcionales generados a partir de uno o varios módulos ontogenéticos). Al mismo tiempo, la alteración de cualquiera de tales módulos ontogenéticos (por ejemplo, mediante la mutación de un determinado gen) o (neuro)funcionales (por ejemplo, a causa de la ocurrencia de algún daño traumático) podrá afectar simultáneamente, en momentos diferentes del desarrollo y con consecuencias diversas, a la FL y a otras capacidades cognitivas. Esta circunstancia es la que permite, en último extremo, seguir manteniendo la hipótesis innatista (cf. Longa y Lorenzo 2008, p. 548). También contribuiría a ello la propia hipótesis de que el acoplamiento entre los sistemas externos sería obligada en presencia de un mínimo de estímulos externos, dependiendo igualmente, como ya se ha indicado, de leyes generales encargadas de la regulación de la organización de los sistemas biológicos. Por un lado, porque la mayor parte de los genes relacionados con el lenguaje estarían invo- 
lucrados en el desarrollo de dichos sistemas externos (si suscribimos la tesis minimalista más fuerte, lo estaría la totalidad de ellos). Por otro, porque el desarrollo de la FL seguiría dependiendo de información no derivable de la experiencia (en definitiva, innata), aunque ya no sería únicamente genética, sino también epigenética, ontogenética o dependiente de factores genéricos de naturaleza fisicoquímica. De hecho, y como señalan Bateson y Mamelli 2007, p. 823, esta «canalization (i.e. the developmental buffering of phenotypic traits against genetic and environmental perturbations) offers yet another way (besides genes themselves) of interpreting Chomksy's claims about the development of linguistic abilities» (Bateson y Mamelli 2007, p. 823).

En consecuencia, parece que esta concepción minimalista de la FL se ajusta mejor que otras (y desde luego, que los modelos chomskyanos preminimalistas, que siguen en boga en determinados ámbitos de la Lingüística, especialmente en el campo de la adquisición del lenguaje) a nuestro conocimiento actual acerca del modo en que tiene lugar el desarrollo de los seres vivos: con independencia de su idiosincrasia en términos fenotípicos, es evidente que la FL no puede constituir ninguna excepción a este respecto.

\section{Conclusiones}

Las evidencias discutidas en este trabajo parecen legitimar el giro biológico (biolingüístico, si se quiere) experimentado por la investigación lingüística en los últimos años. Considerar la FL como un componente de la mente, y el lenguaje, como un resultado de la actividad cerebral, parecen demandas más que razonables a la luz de dichas evidencias. Pero también lo sería la conveniencia de fraccionarlo en diferentes componentes de complejidad biológica diversa. Si bien los avances técnicos experimentados en los últimos años por la Genética, la Biología Molecular y la Neurobiología hacen factible esta posibilidad, la genuina dificultad a la que se enfrenta un programa de investigación biológica del lenguaje con esta orientación no estriba realmente en lograr identificar y caracterizar estructuralmente dichos componentes. Antes bien, el principal reto consiste en lograr proponer un modelo capaz de describir y explicar adecuadamente la manera en que tales componentes interactúan a todos los niveles de complejidad biológica con objeto de regular de forma coordinada la aparición de la FL al término del desarrollo y de permitir la representación de las unidades lingüísticas y las tareas de computación inherentes al procesamiento del lenguaje en el individuo adulto. Por el momento, lo que parece indudable es que la mayoría de los modelos neurolingüísticos y de adquisición del lenguaje (y especialmente los de mayor aceptación hasta este 
momento) deberían reformularse a la luz de los conocimientos existentes actualmente acerca de los fundamentos genéticos y neurobiológicos de la FL (y de la cognición), pero sobre todo, del modo en que se regulan y tienen lugar los procesos de desarrollo en los seres vivos. En nuestro caso, la discusión se ha centrado en el examen de los modelos neurolingüísticos y adquisicionistas que se proclaman innatistas y modularistas. La conclusión fundamental ha sido que, si bien también en este caso dicha reformulación resulta necesaria (y un intento particularmente atractivo a este respecto lo representan los modelos de la FL derivados del Programa Minimalista chomskyano), el concepto de modularidad debe seguir vindicándose como imprescindible, en tanto que propiedad fundamental de todos los niveles de organización biológica (también de la FL), si se quiere llegar a comprender la genuina naturaleza del lenguaje.

\section{REFERENCIAS BIBLIOGRÁFICAS}

AMErican Psychiatric Association (1994): Diagnostic and statistical manual of mental disorders (DSM-IV), Washington, American Psychiatric Association.

Anderson, S. R. y LightFoot, D. W. (1999): «The human language faculty as an organ», Annual Review of Physiology 62, pp. 697-722.

BAKER, C. L. (1979): «Syntactic theory and the projection problem», Linguistic Inquiry 10, pp. 533-581.

BALABAN, E. (2006): «Cognitive developmental biology: history, process and fortune's wheel», Cognition 101, pp. 298-332.

BALARI, S. y LORENZO, G. (2008): «Pere Alberch's developmental morphospaces and the evolution of cognition», Biol Theory 3, pp. 297-304.

- (2009): «Computational phenotypes. Where the teory of computation meets evo-devo», Biolinguistics 3, pp. 2-61.

Balari, S.; Benítez Burraco, A.; Longa, V. M. y Lorenzo, G. (en prensa): «The fossils of language: What are they, who has them, how did they evolve?», en Boeckx, C. y Grohmann, K. (eds), The Cambridge handbook of Biolinguistics, Cambridge, Cambridge University Press.

Barrett, H. C. y KuRzban, R. (2006): «Modularity in cognition: framing the debate», Psychological Review 113, pp. 628-647.

BATES, E.; BRETHERTON, I. y SNYDER, L. (1988): From first words to grammar: Individual differences and dissociable mechanisms, Nueva York, Cambridge University Press.

BATES, E. A.; THAI, D. y JANOWSKY, J. (1992): «Early language development and its neural correlates», en Rapi, I. y Segalowitz, S. (eds.), Handbook of Neuropsychology, Vol. 7, Child Neuropsychology, Ámsterdam, Elsevier, pp. 69-110.

Bateson, P. y Mameldi, M. (2007): «The innate and the acquired: Useful clusters or a residual distinction from folk biology?», Developmental Psychobiology 49, pp. 818-831.

Bellugi, U.; Lichtenberger, L.; Mills, D.; Galaburda, A. y Korenberg, J. R. (1999): «Bridging cognition, the brain and molecular genetics: Evidence from Williams syndrome», Trends in Neuroscience 22, pp. 197-207. 
Bellugi, U.; Korenberg, J. R. y Klima, E. S. (2001): «Williams syndrome: An exploration of neurocognitive and genetic features», Clinical Neuroscience Research 1, pp. 217-229.

Benítez Burraco, A. (2005): «Caracterización neuroanatómica y neurofisiológica del lenguaje humano», RSEL 35, pp. 461-494.

- (2008): «La cuestión de lo innato en la adquisición del lenguaje», RSEL 38, pp. 33-66.

- (2009a): «La evolución del lenguaje: algunos parámetros relevantes y un escenario lingüístico molecularmente plausible (y viceversa)», Verba 36, pp. 155-194.

- (2009b): Genes y lenguaje: aspectos ontogenéticos, filogenéticos y cognitivos, Barcelona, Reverté.

Bergman, A. y Siegal, M. (2002): «Evolutionary capacitance as a general feature of complex gene networks», Nature 424, pp. 549-552.

Bishop, D. V. M. (2002): «The role of genes in the aetiology of specific language impairment», Journal of Communication Disorders 35, pp. 311-328.

Boumman, J.; Maia, A. S.; Camoletto, P. G.; Posthuma, G.; Roubos, E. W.; Oorschot, V. M.; Klumperman, J. y Verhage, M. (2004): «Quantification of synapse formation and maintenance in vivo in the absence of synaptic release», Neuroscience 126, pp. 115-126.

Breuker, C. J.; Debat, V. y Klingenberg, C. P. (2006): «Functional evo-devo», Trends in Ecology and Evolution 21, pp. 488-492.

BULLER, D. J. (2005): Adapting minds: Evolutionary psychology and the persistent quest for human nature, Cambridge, MIT Press.

CARroll, S. B. (2005): Endless forms most beautiful. The new science of evo-devo and the making of the animal kingdom, Nueva York, W.W. Norton \& Co.

Catts, H. W.; Adlof, S. M.; Hogan, T. P. y Weismer, S. E. (2005): «Are specific language impairment and dyslexia distinct disorders?», Journal of Speech, Language and Hearing Research 48, pp. 1378-1396.

CHOMsky, N. (1956): «Three models for the description of language», IEEE Transactions on Information Theory 2, pp. 113-124.

- (1959): «On certain formal properties of grammars», Information and Control 2, pp. 137-167.

- (1977): Essays on form and interpretation, Nueva York, Elsevier North Holland.

- (1980): Rules and representations, Oxford, Basil Blackwell.

- (1986): Knowledge of language: Its nature, origin and use, Nueva York, Prager.

- (1995): The minimalist program, Cambridge, MIT Press.

- (2000a): The architecture of language, Nueva Delhi, Oxford University Press.

- (2000b): «Minimalist inquiries: The framework», en Martin, R.; Michaels, D. y Uriagereka, J. (eds.), Step by step. Papers in minimalist syntax in honour of Howard Lasnik, Cambridge, MIT Press, pp. 89-155.

- (2001): Beyond explanatory adequacy, Cambridge, MIT Press.

- (2005): «Three factors in language design», Linguistic Inquiry 36, pp. 1-22.

Coltheart, M. (1999): «Modularity and cognition», Trends in Cognitive Sciences 3, pp. 115-120.

CRAIN, S. (1991): «Language acquisition in the absence of experience», Behavioural and Brain Sciences 14, pp. 597-650. 
DEACON, T. W. (2000): «Evolutionary perspectives on language and brain plasticity», Journal of Communication Disorders 33, pp. 273-291.

Dehaene, S.; Dupoux, E.; Mehler, J.; Cohen, L.; Perani, D.; van de Moortele, P.-F.; LeHBRICI, S. y LE BiHAN, D. (1997): «Anatomical variability in the cortical representation of first and second languages», Neuroreport 17, pp. 3809-3815.

Donnai, D. y Karmiloff-Smith, A. (2000): «Williams syndrome: From genotype through to the cognitive phenotype», American Journal of Medical Genetics 97, pp. 164-71.

Dronkers, N. F.; Redfern, B. B. y KNight, R. T. (2000): «The neural architecture of language disorders», en Gazzaniga, M. S. (ed.), The new cognitive Neurosciences, Cambridge, MIT Press, pp. 949-961.

DufFY, J. R. (2005): Motor speech disorders, St Louis, Elsevier Mosby.

Elman, J.; Bates, E.; Johnson, M.; Karmiloff-Smith, A.; Parisi, D. y Plunkett, K. (1996): Rethinking innateness: A connectionist perspective on development, Cambridge, MIT Press.

Felleman, D. J. y VAN Essen, D. C. (1991): «Distributed hierarchical processing in the primate cerebral cortex», Cerebral Cortex 1, pp. 1-47.

FisHER, S. E. y SCHARFF, C. (2009): «FOXP2 as a molecular window into speech and language», Trends in Genetics 25, pp. 166-177.

FoDOR, J. A. (1983): The modularity of mind. An essay on faculty psychology, Cambridge, MIT Press.

FRITH, U. (1986): «A developmental framework for developmental dyslexia», Annals of Dyslexia 36, pp. 69-81.

Gibson, K. M.; Wappner, R. S.; Jooste, S.; Erasmus, E.; Mienie, L. J.; Gerlo, E.; Desprechins, B. y De MeIRLeIR, L. (1998): «Variable clinical presentation in three patients with 3-methylglutaconyl-coenzyme A hydratase deficiency», Journal of Inherited Metabolic Disease 21, pp. 631-638.

GLEITMAN, L. (1990): «The structural sources of verb meanings», Language Acquisition 1, pp. 3-55.

Goldman, J. S.; Farmer, J. M.; WoOd, E. M.; Johnson, J. K.; Boxer, A.; Neuhaus, J.; Lomen-Hoerth, C.; Wilhelmsen, K. C.; Lee, V. M.-Y.; Grossman, M. y Miller, B. L. (2005): «Comparison of family histories in FTLD subtypes and related tauopathies», Neurology 65, pp. 1817-1819.

GopNIK, M. (1997): «Language deficits and genetic factors», Trends in Cognitive Sciences 1, pp. 5-9.

GotTLIEB, G. (1997): Synthesizing nature-nurture, Mahwah, Lawrence Erlbaum.

GRAYBIEL, A. M. (1995): «Building action repertoires: Memory and learning functions of the basal ganglia», Current Opinion in Neurobiology 5, pp. 733-741.

GREENFIELD, P. M. (1991): «Language, tools and brain: the ontogeny and phylogeny of hierarchically organized sequential behavior», Behavioral and Brain Sciences 14 , pp. 531-577.

GRIFFITHS, P. E. (2007): «Evo-Devo meets the mind: Towards a developmental evolutionary psychology», en Brandon, R. y Sansom, R. (eds.), Integrating Evolution and Development: From theory to practice, Cambridge, MIT Press, pp. 195-225.

GrifFiths, P. E. y GRAY, R. D. (2004): «The developmental systems perspective: Organism-environment systems as units of evolution», en Preston, K. y Pigliucci, M. (eds.), Phenotypic integration: Studying the ecology and evolution of complex phenotypes, Oxford, Oxford University Press, pp. 409-431. 
Gusella, J. F. y MacDonald, M. E. (2006): «Huntington's disease: Seeing the pathogenic process through a genetic lens», Trends in Biochemical Sciences 31, pp. 533-540.

HALL, B. K. y Olson, W. M. (2003): «Introduction: Evolutionary developmental mechanisms», en Hall, B. K. y Olson, W. M. (eds.), Keywords \& concepts in evolutionary developmental Biology, Cambridge, Harvard University Press, pp. xiii-xvi.

Hannula-Jouppi, K.; Kaminen-Ahola, N.; Taipale, M.; Eklund, R.; Nopola-Hemmi, J.; KAARIAINEN, H. y KERE, J. (2005): «The axon guidance receptor gene ROBO1 is a candidate gene for developmental dyslexia», PLoS Genetics 1, p. 50.

Hauser, M. D.; Chomsky, N. y Fitch, W. T. (2002): «The faculty of language: What is it, who has it, and how did it evolve?», Science 298, pp. 1569-1579.

Hickok, G., Bellugi, U. y Jones, W. (1995): «Asymmetrical ability», Science 270, pp. 219-220.

Hofmann, H. A. (2003): «Functional genomics of neural and behavioural plasticity», Journal of Neurobiology 54, pp. 272-282.

Johnson, M. H. (2003): «Development of human brain functions», Biological Psychiatry 54, pp. 1312-1316.

Jones, W.; Hickok, G.; Rossen, M. L. y Bellugi, U. (1998): Dissociations in cognitive development: Differential effects from two genetically based syndromes (Technical Report CND-9805), University of California, Centre for Research in Language, Project in Cognitive and Neural Development.

Karmiloff-Smith, A.; Tyler, L. K.; Voice, K.; Sims, K.; Udwin, O.; Davies, M. y Howlin, P. (1998): «Linguistic dissociations in Williams Syndrome: Evaluating receptive syntax in on-line and off-line tasks», Neuropsychologia 36, pp. 342-351.

KARMIloff-Smith, A. (1992): Beyond modularity: A developmental perspective on cognitive science, Cambridge, MIT Press.

- (1998): «Development itself is the key to understanding developmental disorders», Trends in Cognitive Sciences 2, pp. 389-398.

- (2006): «Williams syndrome», en Brown, K. (ed.), Encyclopaedia of language and linguistics, Oxford, Elsevier, Vol. 13, pp. 585-589.

- (2008): «Research into Williams syndrome: The state of the art», en Nelson, C. A. y Luciana, M. (eds.), Handbook of developmental cognitive neuroscience, Cambridge, MIT Press, pp. 691-700.

Kaufmann, W. E. y Worley, P. F. (1999): «Neural activity and immediate early gene expression in the cerebral cortex», Mental Retardation and Developmental Disabilities Research Review 5, pp. 41-50.

KIRSCHNER, M. y GERHART, J. (2005): The plausibility of life: Resolving Darwin's dilemma, New Haven, Yale University Press.

Kitano, H. (2004): «Biological robustness», Nature Rev. Genet. 5, pp. 826-837.

Korzumi, H. (2004): "The concept of 'developing the brain': A new natural science for learning and education», Brain and Development 26, pp. 434-441.

KorenberG, J. R.; Dai, L.; Bellugi, U.; Jarvinen-Pasley, A.; Mills, D. L.; Galaburda, A.; Reiss, A. L. y Pober, B. R. (2008): «Deletion of 7q11.23 genes and Williams syndrome», en Epstein, C. J.; Erickson, R. P. y Wynshaw-Boris, A. (eds.), Inborn errors of development. The molecular basis of clinical disorders of morphogenesis, Nueva York, Oxford University Press, pp. 1544-1552. 
Lai, C. S.; Fisher, S. E.; Hurst, J. A.; Vargha-Khadem, F. y Monaco, A. P. (2001): «A novel forkhead-domain gene is mutated in a severe speech and language disorder», Nature 413, pp. 519-523.

LiEBERMAN, P. (2000): Human language and our reptilian brain. The subcortical bases of speech, syntax and thought, Cambridge, Harvard University Press.

- (2002): «On the nature and evolution of the neural bases of human language», American Journal of Physical Anthropology 45, pp. 36-62.

- (2006): Toward an evolutionary biology of language, Cambridge, Harvard University Press.

Livingstone, M. S.; Rosen, G. D.; Drislane, F. W. y Galaburda, A. M. (1991): «Physiological and anatomical evidence for a magnocellular defect in developmental dyslexia», Proceedings of the National Academy of Sciences USA 88, pp. 7943-7947.

LONGA, V. M. y Lorenzo, G. (2008): «What about a (really) minimalist theory of language acquisition?», Linguistics 46, pp. 541-570.

LoRENzo, G. (2006): El vacío sexual, la tautología natural y la promesa minimalista, Madrid, Antonio Machado Libros.

- (2009): «Los límites de la selección natural y el evo-minimalismo. Antecedentes, actualidad y perspectivas del pensamiento chomskyano sobre los orígenes evolutivos del lenguaje», Verba 35, pp. 387-421.

Love, A. C. (2007): «Functional homology and homology of function: Biological concepts and philosophical consequences», Biology and Philosophy 22, pp. 691-708.

Lovegrove, W. J.; Bowling, A.; BAdcock, D. y Blackwood, M. (1980): «Specific reading disability: Differences in contrast sensitivity as a function of spatial frequency», Science 210, pp. 439-440.

Lust, B. (2006): Child language: Acquisition and growth, Cambridge, Cambridge University Press.

Marcus, G. F. (2006): «Cognitive architecture and descent with modification», Cognition 101, pp. 443-465.

Marsden, C. D. y Obeso, J. A. (1994): «The functions of the basal ganglia and the paradox of sterotaxic surgery in Parkinson's disease», Brain 117, pp. 877-897.

Martens, M. A.; Wilson, S. J. y Reutens, D. C. (2008): «Williams syndrome: A critical review of the cognitive, behavioral, and neuroanatomical phenotype», Journal of Child Psychology and Psychiatry 49, pp. 576-608.

Matthews, P. H. (2001): A short history of structural Linguistics, Cambridge, Cambridge University Press.

MaYnard Smith, J. (2000): «The concept of information in Biology», Philosophy of Science 67, pp. 177-194.

Merinero, B.; Perez-Cerda, C.; Font, L. M.; Garcia, M. J.; Aparico, M.; Lorenzo, G.; Martinez Pardo, M.; Garzo, C.; Martinez-Bermejo, A.; Castroviejo, I. P.; Christensen, E. y Ugarte, M. (1995): «Variable clinical and biochemical presentation of seven Spanish cases with glutaryl-CoA-dehydrogenase deficiency», Neuropediatrics 26, pp. 238-242.

Mervis, C. B. y Becerra, A. M. (2007): «Language and communicative development in Williams syndrome», Mental Retardation and Developmental Disabilities Research Review 13, pp. 3-15. 
Mills, D. L.; Llamas, T. y Doyle, T. (2003): «Brain and language development in infants and children with William's Syndrome», The society for research in child development, Biennial meeting, Tampa, Florida, abril de 2003. Disponible en <http://bbcd.bangor.ac.uk/documents/WSlangAKS_DM.pdf> [12-07-2012].

Mohr, J. P.; Pessin, M. S.; Finkelstein, S.; Funkenstein, H. H.; Duncan, G. W. y DAvIS, K. R. (1978): «Broca aphasia: Pathologic and clinical», Neurology 28, pp. 311-24.

Monchi, O.; Petrides, P.; Petre, V.; Worsley, K. y Dagher, A. (2001): «Wisconsin Card Sorting revisited: Distinct neural circuits participating in different stages of the task identified by event related functional magnetic resonance imaging», Journal of Neuroscience 21, pp. 7733-7741.

Müller, G. B. (2007): «Evo-devo: Extending the evolutionary synthesis», Nature Reviews Genetics 8, pp. 943-949.

- y Newman, S. A. (eds) (2005): «Evolutionary innovation and morphological novelty», Journal of Experimental Zoology. Part B: Molecular and Developmental Evolution 304, Special issue.

-; Behen, M. E.; Rothermel, R. D.; Muzik, O.; Chakraborty, P. K. y Chugani, H. T. (1999): «Brain organization for language in children, adolescents, and adults with left hemisphere lesion: a PET study», Progress in Neuropsychopharmacology and Biological Psychiatry 23, pp. 657-668.

Newman, S. A. y Comper, W. D. (1990): «'Generic' physical mechanisms of morphogenesis and pattern formation», Development 110, pp. 1-18.

Newman, S. A.; Forgacs, G. y Müller, G. B. (2006): «Before programs: The physical origination of multicellular forms», International Journal of Developmental Biology 50, pp. 289-299.

Newmeyer, F. J. (1997): «Genetic dysphasia and linguistic theory», Journal of Neurolinguistics 10, pp. 47-73.

Nicolson, R. I. y FAWCETT, A. J. (2006): «Do cerebellar deficits underlie phonological problems in dyslexia?», Developmental Science 9, pp. 259-262.

Nobre, A. C. y PlunkettT, K. (1997): «The neural system of language: Structure and development», Current Opininion in Neurobiology 7, pp. 262-266.

NoRBurY, C. F. (1995): «Barking up the wrong tree? Lexical ambiguity resolution in children with language impairments and autistic spectrum disorders», Journal of Experimental Child Psychology 90, pp. 142-171.

O'GRADY, W. (2003): «The radical middle: Nativism without universal grammar», en Doughty, C. J. y Long, M. H. (eds.), Handbook of second language acquisition, Malden, Blackwell, pp. 43-62.

Oyama, S. (1985): The ontogeny of information. Developmental systems and evolution, Cambridge, Cambridge University Press.

Oyama, S.; Griffiths, P. E. y Gray, R. D. (eds.) (2001): Cycles of Contingency. Developmental systems and evolution, Cambridge, MIT Press.

Paterson, S. J.; Brown, J. H.; Gsödl, M. K.; Johnson, M. H. y Karmiloff-Smith, A. (1999): «Cognitive modularity and genetic disorders», Science 286, pp. 23552357.

Pinker, S. (1994): The language instinct, Londres, Penguin Books. 
PoEPPEL, D. y EMBICK, D. (2005): «The relation between linguistics and neuroscience», en Cutler, A. (ed.), Twenty-first century psycholinguistics: four cornerstones, Hillsdale, Lawrence Erlbaum Associates, pp. 103-120.

Pullum, G. K. y Scholz, B. C. (2002): «Empirical assessment of stimulus poverty arguments», The Linguistic Review 19, pp. 9-50.

RAFF, R. A. (1996): The shape of life: Genes, development and the evolution of animal form, Chicago, University of Chicago Press.

RAmus, F. (2006): «Genes, brain, and cognition: A roadmap for the cognitive scientist», Cognition 101, pp. 247-269.

Rapin, I. y Allen, D. A. (1983): «Developmental language disorders: Nosologic considerations», en Kirk, U. (ed.), Neuropsychology of language, reading and spelling, Nueva York, Academic Press, pp. 155-184.

Rosenberg, A. (1997): «Reductionism redux: Computing the embryo», Biological Philosophy 12, pp. 445-470.

Saxton, M. (2010): Child language: Acquisition and development, Londres, Sage Publications.

SCHACTER, J. (1990): «On the issue of completeness in second language acquisition", Second Language Research 6, pp. 93-124.

Schwartz, M. F.; Linebarger, M. C.; Saffran, E. M. y Pate, D. C. (1987): «Syntactic transparency and sentence interpretation in aphasia", Language and Cognitive Processes 2, pp. 85-113.

SEIDENBERG, M. S. y MACDONALD, M. C. (1999): «A probabilistic constraints approach to language acquisition and processing», Cognitive Sciences 23, pp. 569-588.

Selnes, O. A.; Knopman, D. S.; Niccum, N.; Rubens, A. B. y Larson, D. (1983): «Computed tomographic scan correlates of auditory comprehension deficits in aphasia: A prospective recovery study», Annals of Neurology 13, pp. 558-566.

Shapiro, L. P.; Gordon, B.; HACK, N. y Killackey, J. (1993): «Verb-argument structure processing in complex sentences in Broca's and Wernicke's aphasia», Brain and Language 45, pp. 423-447.

Shaywitz, S. E.; Shaywitz, B. A.; Pugh, K. R.; Fulbright, R. K.; Constable, R. T.; Mencl, W. E.; Shankweiler, D. P.; Liberman, A. M.; Skudlarski, P.; Fletcher, J. M.; Katz, L.; Marchione, K. E.; Lacadie, C.; Gatenby, C. y Gore, J. C. (1998): "Functional disruption in the organization of the brain for reading in dyslexia», Proceedings of the National Academy of Sciences USA 95, pp. 2636-2641.

Shriberg, L. D.; Tomblin, J. B. y McSweeny, J. L. (1999): «Prevalence of speech delay in 6-year-old children and comorbidity with language impairment», Journal of Speech, Language and Hearing Research 42, pp. 1461-1481.

Shu, W.; YAnG, H.; Zhang, L.; Lu, M. M. y Morrisey, E. E. (2001): «Characterization of a new subfamily of wingedhelix/forkhead (Fox) genes that are expressed in the lung and act as transcriptional repressors», Journal of Biological Chemistry 276, pp. 27488-27497.

Smith, L. B. y Thelen, E. (2003): «Development as a dynamic system», Trends in Cognitive Science 7, pp. 343-348.

Smith, N. V. y Tsimpli, I. M. (1995): The mind of a savant: Language-learning and modularity, Oxford, Blackwell.

Sмiтh, S. D. (2007): «Genes, language development, and language disorders», Mental Retardation and Developmental Disabilities Research Review 13, pp. 96-105. 
-; Gilger, J. W. y Pennington, B. F. (1996): «Dyslexia and other specific learning disorders», en Rimoin, D. L.; Connor, J. M. y Pyeritz, R. E. (eds.), Principles and practice of medical genetics, Nueva York, Churchill Livingstone, pp. 1767-1789.

SPELKE, E. S. (1998): «Nativism, empiricism, and the origins of knowledge», Infant Behaviour and Development 21, pp. 181-200.

SPERBER, D. (2001): «In defence of massive modularity», en Emmanuel, D. (ed), Language, brain, and cognitive development: Essays in honour of Jacques Mehler, Cambridge, MIT Press, pp. 47-57.

St. George, M.; Mills, D. y Bellugi, U. (2000): «ERPs during auditory language comprehension in Williams Syndrome: The effects of word frequency, imageability and length on word class», NeuroImage 11, p. 357.

Stein, J. y WALSH, V. (1997): «To see but not to read: The magnocellular theory of dyslexia», Trends in Neuroscience 20, pp. 147-152.

Sterelny, K. y Griffiths, P. E. (1999): Sex and death: An introduction to the philosophy of biology, Chicago, University of Chicago Press.

TAger-Flusberg, H. (2006): «Defining language phenotypes in autism», Clinical Neuroscience Research 6, pp. 219-224.

TALLAL, P. y PIERCY, M. (1973): «Defects of nonverbal auditory perception in children with developmental dysphasia», Nature 241, pp. 468-469.

TAllal, P.; Sainburg, R. y Jernigan, T. (1991): «The neuropathology of developmental dysphasia: behavioral, morphological, and physiological evidence for a pervasive temporal processing disorder», Reading and Writing 3, pp. 363-377.

Temple, E.; Poldrack, R. A.; Protopapas, A.; Nagarajan, S.; Salz, T.; Tallal, P.; Merzenich, M. M. y Gabrieli, J. D. E. (2000): «Disruption of the neural response to rapid acoustic stimuli in dyslexia: Evidence from functional MRI», Proceedings of the National Academy of Sciences USA 97, pp. 13907-13912.

True, J. R. y CARroll, S. B. (2002): «Gene co-option in physiological and morphological evolution», Annual Review of Cell and Developmental Biology 18, pp. 53-80.

UlLman, M. T. (2001): «The declarative/procedural model of lexicon and grammar», Journal of Psycholinguist Research 30, pp. 37-69.

Vargha-Khadem, F.; Watkins, K. E.; Price, C. J.; Ashburner, J.; Alcock, K. J.; Connelly, A.; Frackowiak, R. S. J.; Friston, K. J.; Pembrey, M. E.; Mishkin, M.; Gadian, D. G. y Passingham, R. E. (1998): «Neural basis of an inherited speech and language disorder», Proceedings of the National Academy of Sciences USA 95, pp. 12695-12700.

Verhage, M.; Maia, A. S.; Plomp, J. J.; Brussaard, A. B.; Heeroma, J. H.; Vermeer, H.; Toonen, R. F.; Hammer, R. E.; van den Berg, T. K.; Missler, M.; Geuze, H. J. y SüdHOF, T. C. (2000): «Synaptic assembly of the brain in the absence of neurotransmitter secretion», Science 287, pp. 864-869.

WAGNER, G. P. (1996): «Homologues, natural kinds and the evolution of modularity», American Zoology 36, pp. 36-43.

- y Altenberg, L. (1996): «Complex adaptations and the evolution of evolvability», Evolution 50, pp. 967-976.

WINTHER, R. G. (2001): «Varieties of modules: Kinds, levels, origins, and behaviors», Journal of Experimental Zoology 291, pp. 116-129. 